\title{
¿Cross-Shore Deformation of a Surfzone-Released Dye Plume by an Internal Tide on the Inner Shelf
}

\author{
DereK J. Grimes, FAlK Feddersen, ANd SARAH N. GiddingS \\ Scripps Institution of Oceanography, La Jolla, California \\ GENO PAWLAK \\ University of California, San Diego, La Jolla, California
}

(Manuscript received 21 February 2019, in final form 11 October 2019)

\begin{abstract}
An inner-shelf (IS) dye plume that formed following a 3.84-h early morning surfzone (SZ) dye release off of Imperial Beach, California, is analyzed with in situ and aerial remotely sensed observations. Midmorning, $5 \mathrm{~h}$ after release start, the IS plume extended $800 \mathrm{~m}$ offshore (or $\approx 8 L_{\mathrm{sz}}$, where $L_{\mathrm{sz}}$ is the surfzone width) and was surface intensified. Over the next $\approx 2 \mathrm{~h}$, the IS plume deformed (narrowed) cross-shore with the offshore front progressing onshore at $\approx 5 \mathrm{~cm} \mathrm{~s}^{-1}$, deepened by up to $3 \mathrm{~m}$, and elongated alongshore at $\approx 4.5 \mathrm{~cm} \mathrm{~s}^{-1} \mathrm{~km}^{-1}$ (at $\approx 2.5 L_{\mathrm{sz}}$ ). Coincident with IS plume deformation and deepening, IS isotherms also deepened, with relatively stable IS plume joint dye and temperature statistics. Offshore tracer transport and subsequent IS plume deformation and deepening likely resulted from two phases of the diurnal internal tide (DIT). During and after deformation, the IS plume did not reenter the warm surfzone, which potentially acted as a thermal barrier. High-frequency internal waves (HF IWs) propagated through the IS plume at $\approx 9 \mathrm{~cm} \mathrm{~s}^{-1}$ and dissipated onshore of $4 L_{\mathrm{sz}}$. Surface HF IW signal was elevated in the plume elongation region, suggesting a linkage between plume elongation and either the DIT or HF IW. This IS plume evolution differs from previous SZ tracer releases, highlighting the effects of release timing relative to the solar cycle or the internal tide.
\end{abstract}

\section{Introduction}

The cross-shore exchange of tracers across the surfzone (SZ; region of depth limited surface gravity wave breaking) and the inner shelf (IS; region offshore of surfzone to $\approx 15$-m water depth) is integral to coastal human and ecosystem health (e.g., Barbier et al. 2011). For example, the transfer of human pathogens across the SZ onto the IS dilutes SZ concentrations and improves degraded coastal water quality (e.g., Grant et al. 2005). Shoreward larval transport from the shelf to inner-SZ intertidal recruitment sites is critical to coastal ecosystems (e.g., Pineda et al. 2007). Broadly, many different mechanisms are known to contribute to crossshore exchange of tracers, that is, across SZ, IS, or both (e.g., Morgan et al. 2018; Washburn and McPhee-Shaw

๑ Denotes content that is immediately available upon publication as open access.

Corresponding author: Derek J. Grimes, dgrimes@ucsd.edu
2013; Lentz and Fewings 2012). However, the interaction and combination of both SZ and IS processes across a range of time scales (such as rip currents and internal waves and tides) and their effect on cross-shore tracer exchange is poorly understood.

SZ tracer dispersion is predominantly driven by breaking surface gravity waves. Dissipation of surface gravity waves supplies turbulence (e.g., Feddersen 2012), vertically mixing both temperature and tracers (e.g., Hally-Rosendahl et al. 2014). Breaking waves also drive SZ alongshore currents (e.g., Longuet-Higgins 1970a,b) and vertical vorticity (Clark et al. 2012). For alongshore uniform nearshore morphologies (Feddersen and Guza 2003), tracer exchange does not generally depend on the alongshore location of tracer release, but may be sensitive to the release time. Alongshore uniform cross-SZ tracer dispersion is attributed to SZ vertical eddy vorticity (Clark et al. 2010). In contrast, for alongshore variable rip-channeled SZs, short time scale $(<90 \mathrm{~s})$ drifter dispersion is attributed to the strong shear in bathymetrically controlled rip currents (Brown et al. 2009). 
SZ processes also drive exchange with and across the IS. For example, SZ eddies coalesce to form transient rip currents (TRC), ephemeral offshore directed flows that eject SZ water onto the IS (e.g., Johnson and Pattiaratchi 2004), and have been identified as irregular alongshore dye patches on the IS following a late-morning SZ dye release (Hally-Rosendahl et al. 2014). TRCs brought SZ released dye out to $2 L_{\mathrm{sz}}-3 L_{\mathrm{sz}}$ (where $L_{\mathrm{sz}}$ is the width of the SZ) offshore in about $5 \mathrm{~h}$ (Hally-Rosendahl et al. 2015). In barotropic models, TRC driven exchange can be significantly larger than Stokes drift exchange up to several SZ widths from shore, and depends critically on incident wave directional spread (Suanda and Feddersen 2015). On the stratified IS, TRCs can enhance vertical mixing, generating a baroclinic cross-shore circulation (Kumar and Feddersen 2017a) that induces a subsurface crossshore tracer exchange pathway out to $6 L_{\mathrm{sz}}-8 L_{\mathrm{sz}}$ over $12 \mathrm{~h}$ (Kumar and Feddersen 2017b). On rip-channeled beaches, bathymetrically controlled rip currents can circulate water between the SZ and IS, in some cases with little net crossshore exchange due to recirculation (e.g., Brown et al. 2015).

In addition to SZ generated TRCs, other processesspanning a large range of time and space scalescontribute to cross-shore exchange on an alongshore uniform IS (e.g., Lentz and Fewings 2012). On relatively long subtidal $(>33 \mathrm{~h})$ time scales, alongshore upwelling (downwelling) winds can drive cross-shelf circulation on the mid to outer shelf (e.g., Smith 1981). On the shallow IS, cross-shore circulation is weaker and may shut down under unstratified conditions, potentially blocking IS tracer exchange (Lentz 2001; Austin and Lentz 2002). Cross-shore winds also contribute to cross-shelf circulation with response dependent on initial vertical and cross-shore stratification (Horwitz and Lentz 2014).

On the midshelf, semidiurnal and diurnal tidal-band internal waves have been inferred to induce cross-shelf nutrient fluxes (Lucas et al. 2011). On the shallow IS, internal waves can drive considerable temperature fluctuations, even at $h=5$-m depth (Winant 1974), and induce exchange (Pineda 1999). Near-bed cold bores with time scales $1-4 \mathrm{~h}$ have been observed to propagate upslope from 8- to 2-m depth (outer SZ limit) in a manner consistent with an upslope gravity current (Sinnett et al. 2018). High-frequency internal waves (HF IW; periods $\leq$ $1 \mathrm{~h}$ ) in the form of solitary-like waves are often associated with these bores (e.g., Walter et al. 2012; Klymak and Moum 2003). Instability of large amplitude internal tides (IT) can generate smaller-scale (and higher-frequency) IWs (e.g., Holloway et al. 1999) that can contribute to cross-shelf mass flux (e.g., Lamb 1997; Shroyer et al. 2010; Zhang et al. 2015). Thus, internal waves at tidal and HF time scales may contribute to exchange across the IS and potentially even across the SZ.
Cross-shore buoyancy gradients can also influence IS exchange. For instance, nearshore diurnal heating and cooling drives exchange (e.g., Monismith et al. 1990; Farrow and Patterson 1993), with potential to flush the SZ-IS region in roughly a day (Molina et al. 2014). Vertical shear in alongshore flows can also result in Coriolis-driven cross-shore exchange (Ulloa et al. 2018). Alternatively, a strong SZ-IS temperature difference (e.g., midday warmer SZ and colder IS; Hally-Rosendahl et al. 2014) may prevent IW propagation into very shallow water (i.e., <4-m depth; e.g., Omand et al. 2011).

Several previous $\mathrm{SZ}$ dye releases observed cross-shore tracer dispersal onto the IS to $2 L_{\mathrm{sz}}-3 L_{\mathrm{sz}}$ over $2-5 \mathrm{~h}$ (e.g., Grant et al. 2005; Hally-Rosendahl et al. 2014, 2015). However, the mechanism for exchanging tracer farther offshore is not clear and likely involves IS processes across a range of spatiotemporal scales (e.g., HF IW and IT, and diurnal thermal exchange). Furthermore, because these previous SZ dye releases were all mid- to late morning in either May or September in Southern California (with strong solar heating), the effect of release timing on the cross-shore exchange is not clear. Previous IS tracer release experiments in depths of $6<h<12 \mathrm{~m}$ have focused on testing relative dispersion scalings (e.g., Stacey et al. 2000; Fong and Stacey 2003; Jones et al. 2008) and underlying mechanisms, like shear dispersion (e.g., Sundermeyer and Ledwell 2001; Moniz et al. 2014).

Under realistic conditions, a combination of IS processes with a range of spatiotemporal scales are likely to contribute to IS tracer exchange, which can make field observations difficult to contextualize. For example, largescale stratification changes during tracer observations (e.g., Fong and Stacey 2003) can bias dispersion statistics. Even for nearly stationary conditions, the number of independent realizations often is logistically limited, precluding statistical treatment. Additionally, limited observations can make it difficult to attribute the observed tracer evolution to physical processes (e.g., Sundermeyer and Ledwell 2001). Observations of tracer evolution spanning the range of scales (e.g., TRCs to HF IW to IT) are necessary to understand how an SZ-released tracer is exchanged across the IS.

As part of the Cross Surfzone/Inner-Shelf Dye Exchange (CSIDE) experiment (Imperial Beach, California; Fig. 1a), the evolution of an early morning, SZ-released tracer is observed on the IS over $\approx 10 \mathrm{~h}$ and $\approx 10 \mathrm{~km}$ alongshore where tracer plume width varied from 500 to $800 \mathrm{~m}$ (or $5 L_{\mathrm{sz}}-8 L_{\mathrm{sz}}$ ) cross-shore. Dye, temperature, and current observations, as well as averaging methodologies are described in section 2. In section 3, novel IS plume observations from aerial remote and in situ observations are presented. The effect of the internal tide, HF IW, and solar heating on the evolution of the IS tracer plume as well as the potential effect of shoreline tracer release timing 


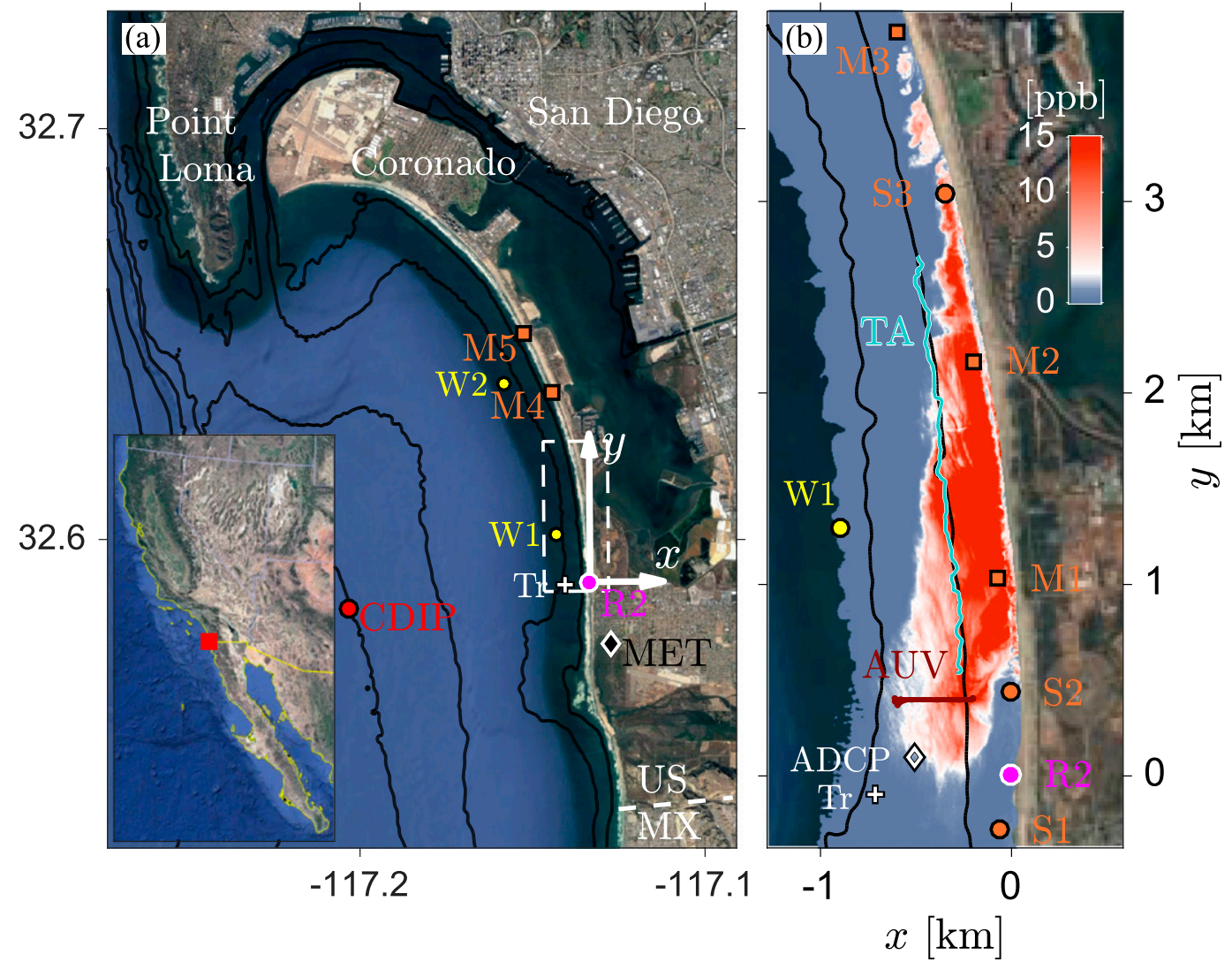

FIG. 1. (a) Map of San Diego Bight study region, with inset to illustrate location of experiment with respect to the California (U.S.)-Baja California (MX) coast. The dye release location R2 (magenta circle), the local $(x, y)$ coordinate axes with lengths of $(2,4) \mathrm{km}$ in white, and white dashed line shows the perimeter of $(\mathrm{b})$. Indicated are the locations of offshore fixed instrumentation: two Wirewalkers (W1 and W2), thermistor mooring (Tr), Coastal Data Information Program (CDIP) wave buoy, and TRNERR meteorological (MET) station. Also shown in (a) are SZ instruments M4 and M5 (orange), north of (b). Bathymetry is derived from the 2012 NOAA tsunami DEM and $h=$ $[6,12,24,36, \ldots] \mathrm{m}$ are contoured in black. (b) Map of surface dye field at 1020 PDT 8 Oct 2015 contoured in parts per billion, along with the locations of IS current meter (ADCP), and SZ instrumentation (M1-M3 and S1-S3). Also shown in (b) are the raw trajectories of the towed array (TA) and AUV transects.

relative to internal tide phase and solar cycle are discussed in section 4. The results are summarized in section 5 .

\section{Methods}

The CSIDE study consisted of three dye tracer releases, conducted in the southern San Diego Bight near the city of Imperial Beach (IB), California (Fig. 1) in fall of 2015. Herein we report on IS observations spanning approximately $11.5 \mathrm{~h}$ following the start of the second release (R2) on 8 October 2015. The San Diego Bight region includes San Diego Bay and is bounded by the United StatesMexico border and Tijuana River Estuary to the south, and Point Loma to the north and west, and includes the cities of IB and Coronado. A broad shoal offshore of the estuary focuses incoming swell (see the 6- and 12-m depth contour in Fig. 1a) resulting in locally complex wave transformation patterns. Between IB and Coronado is a 9-km isthmus that includes Silver Strand State Beach where the 6- and 12-m depth contours are approximately parallel to shore. The coastline curves more rapidly near Coronado before terminating at the north-south-oriented San Diego Bay Inlet. The local right-handed coordinate system originates at the location of the second release, R2 in Figs. 1a and 1b, with positive $x$ increasing onshore and oriented approximately true east, $y$ oriented along-coast at the origin and toward north, and vertical coordinate $z$ is up relative to mean sea level. In addition, a local, shoreline referenced shore-normal coordinate is given by $\tilde{x}$, and $\tilde{z}$ is used to denote vertical measurements relative to the tidally varying sea surface $\eta$.

\section{a. Moored and fixed instrumentation}

Fixed instruments were deployed in the study region for approximately one month (15 September-15 October 
2015) to provide regional scale physical oceanographic conditions (see Fig. 1a). Three moorings provided water column temperature measurements. The southernmost mooring (Tr in Fig. 1) was located approximately on the $h=12-\mathrm{m}$ isobath and consisted of 6 Sea-Bird 56 thermistors sampling at $0.5 \mathrm{~Hz}$ with vertical spacing $\Delta z=1.5 \mathrm{~m}$ beginning at $z=-2.6 \mathrm{~m}$ below mean sea level (MSL). A 1.2-MHz RD Instruments four-beam acoustic Doppler current profiler (ADCP in Fig. 1b) was deployed adjacent to mooring $\operatorname{Tr}(\Delta x=202 \mathrm{~m}, \Delta y=195 \mathrm{~m})$ on roughly the 11-m isobath. The ADCP sampled during daytime from 0800 to 1600 Pacific daylight time (PDT) with a sample rate of $1 \mathrm{~Hz}$ and vertical resolution of $0.5 \mathrm{~m}$. Farther north, two Wirewalker wave powered profilers (Rainville and Pinkel 2001) outfitted with Sea-Bird-49 conductivitytemperature-depth (CTD) sensors and Wetlab ECOTriplet fluorometers (W1 and W2 in Fig. 1a) were deployed on the $h=13$ - and 14-m bathymetry contour, respectively. These Wirewalkers sampled roughly the upper two-thirds of the water column and under typical conditions repeat profiles took $\approx 90 \mathrm{~s}$. Moorings $\mathrm{W} 1$ and W2 were located about 1.4 and $5.7 \mathrm{~km}$ from Tr, respectively, with $\mathrm{W} 1$ and $\mathrm{W} 2$ separated by $4.3 \mathrm{~km}$. Wave data was provided by Coastal Data Information Program (CDIP) IB West buoy number 218 (CDIP in Fig. 1a). Wind speed and direction was provided by the Tijuana River Estuary National Research Reserve meteorological station (denoted MET in Fig. 1a). Additional instrumentation was deployed offshore and inside the Tijuana River Estuary that are not used in this analysis.

\section{b. Surfzone dye release}

The R2 release period started at 0518 PDT (hereafter time of day is presented as $0518 \mathrm{~h}$, and time since release start $t_{r}$ is given in decimal hours) on 8 October 2015 and lasted approximately $3.84 \mathrm{~h}$. A total of $113.6 \mathrm{~L}$ of $21.49 \%$ Rhodamine WT fluorescent dye solution was pumped via a medical-grade peristaltic pump at a rate of $\approx 0.5 \mathrm{Lmin}^{-1}$ into the SZ at a fixed cross-shore position where the depth varied from roughly 0.25 to $0.75 \mathrm{~m}$ with the incoming tide over the release duration. Dye release location temperature was measured with a Sea-Bird-56 thermistor at $1 \mathrm{~Hz}$. The release was chosen to coincide with incident south swell (i.e., driving SZ currents to north) and the incoming phase of the surface tide (i.e., during positive alongshore tidal velocity) to maximize the potential for northward transport.

\section{c. Mobile instrumentation}

Mobile observation began after the start of the dye release with SZ, in situ IS, and aerial remote-sensed platforms (symbols and lines in Fig. 1b). SZ dye and temperature were measured at $1 \mathrm{~Hz}$ for $48 \mathrm{~h}$ after release start with Wetlab ECO-Triplet fluorometer + temperature sensors mounted to poles (S1-S3, Fig. 1b) and with collocated ECO-Triplet fluorometers + Sea-Bird-39 thermistors mounted to anchored mobile carts (M1M5, Fig. 1). These platforms were deployed mid-SZ. The pole-mounted instruments were not moved once deployed, whereas the carts were moved cross-shore with the tide to maintain roughly mid-SZ position.

In situ IS sampling consisted of vessel towed array (TA) and autonomous underwater vehicle (AUV) transects (TA and AUV in Fig. 1b). The TA had 5 Wetlab ECO-Triplet fluorometer + temperature sensors sampling at $1-6 \mathrm{~m}$ below the surface with a vertical spacing between 1 and $2 \mathrm{~m}$. The 2.5-km-long south-north TA transect (cyan and TA in Fig. 1b) was surveyed at approximately $0.6 \mathrm{~m} \mathrm{~s}^{-1}$ from 1107 to $1210 \mathrm{~h}\left(t_{r}=5.80\right.$ $6.85 \mathrm{~h}$ ). The AUV was a REMUS-100 (Hydroid Inc.) equipped with a Sea-Bird-49 CTD and Wetlabs ECOPuck fluorometer. The AUV drove repeated 500-m-long cross-shore and vertical transects (red line and AUV in Fig. 1b) between 0900 and $1200 \mathrm{~h}\left(t_{r}=3.69-6.69 \mathrm{~h}\right)$. Two repeat cross-shore surveys, taking on average $\leq 20 \mathrm{~min}$, were used to generate $(x, z)$ dye and temperature maps. A personal water craft sampled near-surface $(20 \mathrm{~cm})$ dye and temperature in a mow-the-lawn pattern (not shown) that was used to calibrate aerial hyperspectral measurements.

Aerial remote sensing with the Modular Aerial Sampling System (MASS; Melville et al. 2016) was used to estimate georeferenced surface dye concentration and relative temperature. The dye plume was imaged 53 times between 1020 and $1658 \mathrm{~h}\left(t_{r}=5.02-11.65 \mathrm{~h}\right)$. Photomosaic relative sea surface temperature was measured with an infrared camera (8.0-9.2- $\mu \mathrm{m}$ wavelength band). Pushbroom hyperspectral imagery spanning wavelengths of $400-990 \mathrm{~nm}$ in 126 bands was used to estimate surface dye concentration. The raw hyperspectral data has a crosstrack resolution of roughly $1.25 \mathrm{~m}$ (depending on altitude) and was interpolated to a regular $2 \mathrm{~m} \times 2 \mathrm{~m}$ grid (likewise for temperature). The hyperspectral imagery is converted to surface dye concentrations $D(x, y)$ (Fig. 2a), following Clark et al. (2014) by calibrating to coextensive in situ near-surface personal water craft dye measurements (not shown). IS remote hyperspectral dye measurements are likely sensitive to dye vertical structure, therefore this calibration ensures MASS dye estimates are representative of the near-surface $(\tilde{z} \approx-20 \mathrm{~cm})$ dye concentration.

\section{d. Definition of scales and filtering}

The dye and temperature fields varied over a broad range of horizontal length (from meters to kilometers) and time (from minutes to days) scales, owing to the 

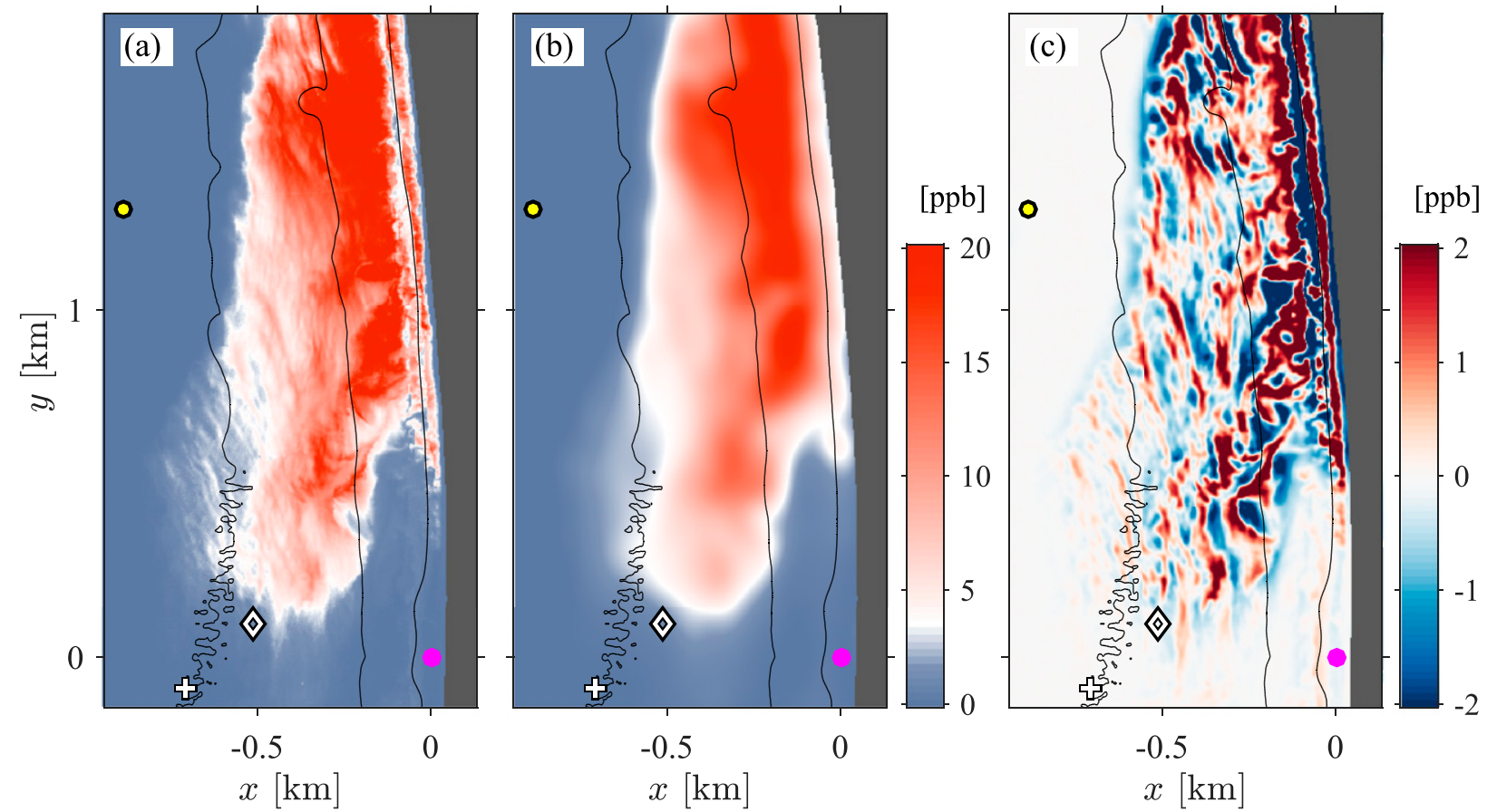

FIG. 2. Example of a spatial filter applied to the IS surface dye field at $1020 \mathrm{~h}\left(t_{r}=5.02 \mathrm{~h}\right)$ : (a) surface dye concentration $D(x, y)$ from calibrated MASS hyperspectral imagery; (b) large-scale dye field $\bar{D}$ with cutoff of $150 \mathrm{~m}$; (c) small-scale dye field $D^{\prime}$ vs $x$ and $y$. The same color scale (0-12 ppb) is used in (a) and (b), and in (c) the scale is $\pm 2 \mathrm{ppb}$. In (a)-(c) gray is land, and black bathymetry contours are $h=$ $[2,6,12] \mathrm{m}$, magenta is the release location, and the location of ADCP (diamond) and IS moorings $\operatorname{Tr}$ (cross) and W1 (yellow) are also indicated.

various processes across the SZ and IS. The range of length scales is seen in the high spatial resolution aerial surface dye measurements (e.g., Fig. 2a). Similarly, moored temperature observations vary at a range of time scales, from diurnal and semidiurnal to periods of approximately $10 \mathrm{~min}$. In the analyses of section 3, dye and temperature fields are decomposed into largeand small-scale fields, denoted by $(\bar{D}, \bar{T})$ and $\left(D^{\prime}, T^{\prime}\right)$, respectively, using a spatial filter with cutoff of approximately $150 \mathrm{~m}$, and results are presented separately to highlight the dominant processes influencing the dye plume at each scale.

For a particular observation source, dye and temperature were filtered with the same method. Aerial dye $D(x, y)$ and temperature $T(x, y)$ imagery were convolved with a two-dimensional $150 \mathrm{~m} \times 150 \mathrm{~m}$ Hamming window. The AUV $D(x, z)$ and $T(x, z)$ transects were objectively mapped using horizontal and vertical decorrelation scales of 150 and $2 \mathrm{~m}$, respectively. The TA $D(y, z)$ and $T(y, z)$ transect was smoothed via convolution with a Hamming window in the time-domain equivalent to an average along-track length scale of approximately $150 \mathrm{~m}$ (i.e., $4 \mathrm{~min}$ underway at $0.6 \mathrm{~m} \mathrm{~s}^{-1}$ ). Mooring $T(t, z)$ and current meter cross-shore velocity $u(t, z)$ were convolved with a 30 -min-wide Hamming window. Results were not sensitive to the windowing function.

The linkage between the $150-\mathrm{m}$ spatial scale filter cutoff and the 30-min time domain filter cutoff is based on the shallow water and flat bottom, mode- 1 linear internal wave (IW) dispersion relationship,

$$
\omega=k \frac{N h}{\pi},
$$

where $N=\left(-g \rho_{o}^{-1} \partial \rho / \partial z\right)^{1 / 2}$ is the buoyancy frequency, $h$ the local water depth, $k$ is the local wavenumber and $\omega$ the frequency of the IW. The vertical temperature time series at $\operatorname{Tr}(h=12 \mathrm{~m})$ was used to compute $N(t, z)$, using a constant salinity of $33.4 \mathrm{psu}$, resulting in the depth and time (0800-1300 $\mathrm{h}$ ) averaged $N=2.3 \times 10^{-2} \mathrm{rad} \mathrm{s}^{-1}$, or $2 \pi / N=4.5 \mathrm{~min}$. Thus, an IW with a wavelength of $150 \mathrm{~m}$ has a period of approximately $30 \mathrm{~min}$. By applying a constant $150-\mathrm{m}$ scale spatial filter both HF IWs (periods $4.5-30 \mathrm{~min}$ ) and TRCs were classified as small scale.

An example surface dye decomposition into large and small scales is shown in Fig. 2. The large-scale (i.e., $>150 \mathrm{~m}$ ) dye field $\bar{D}(x, y)$ (Fig. $2 \mathrm{~b}$ ) captures the boundaries and the peak concentration of the plume. 

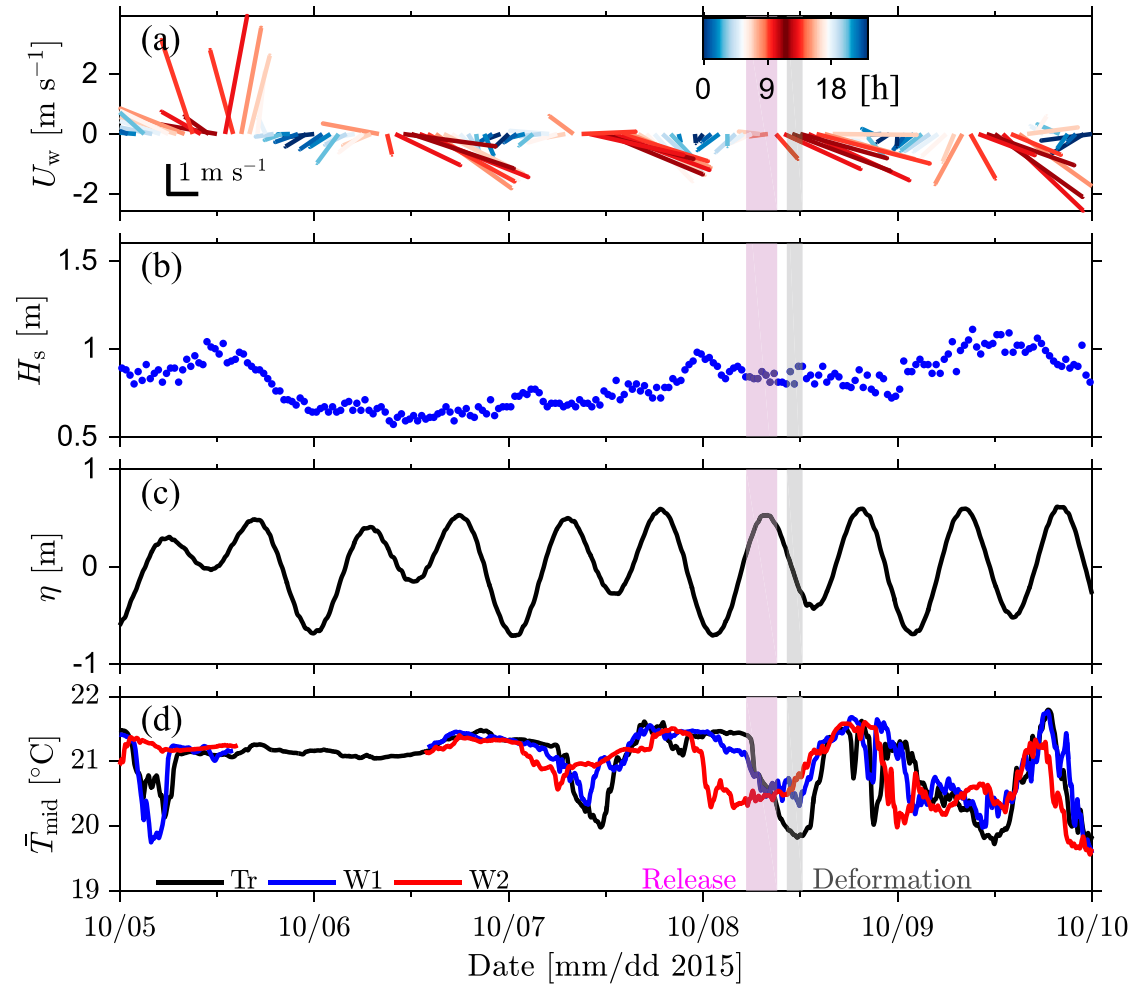

FIG. 3. Five-day time series of CSIDE experiment conditions: (a) TRNERR MET station wind vectors (see Fig. 1) where the line color represents the hour of day; (b) significant wave height $H_{s}$ from CDIP buoy; (c) sea surface elevation $\eta$ from ADCP pressure record; and (d) bandpassed middepth temperature $\bar{T}_{\text {mid }}$ evolution at Tr (black), W1 (blue), and W2 (red). The time period spanning the release $\mathrm{R} 2$ is denoted with a magenta bar and the IS plume deformation period with the gray bar.

Small-scale $(<150 \mathrm{~m})$ dye field $D^{\prime}(x, y)$ (Fig. 2c) variations are roughly $\pm 2 \mathrm{ppb}$, with signatures of wave breaking in the SZ, TRCs at the SZ-IS boundary, as well as HF IW-like features on the IS.

\section{Results}

\section{a. Regional observations and dye release background conditions}

During the experiment, a diurnal sea breeze was typical with onshore wind speeds of $5 \mathrm{~m} \mathrm{~s}^{-1}$, peaking in the afternoon, along with a slight northerly mean of approximately $0.5 \mathrm{~m} \mathrm{~s}^{-1}$ (Fig. 3a). On 4 and 5 October 2015 a storm interrupted this pattern with sustained $8 \mathrm{~m} \mathrm{~s}^{-1}$ southerly winds (Fig. 3a) and $5 \mathrm{~mm}$ of precipitation (not shown). Atmospheric conditions returned to normal by 6 October. On 8 October (first day of R2), the CDIP buoy average significant wave height was $0.84 \mathrm{~m}$ (Fig. $3 \mathrm{~b}$ ), with peak period $\approx 14.3 \mathrm{~s}$ and peak direction $\approx 226^{\circ}$ true (i.e., from SW and driving northward SZ currents). The maximum tidal range in the San Diego Bight is roughly $2 \mathrm{~m}$. During R2, the tidal range was $1.4 \mathrm{~m}$ with a semidiurnal inequality of approximately $20 \mathrm{~cm}$ (Fig. 3c).

The middepth IS temperature variability had a prominent diurnal internal tidal (DIT) signature (Fig. 3d) that was modulated subtidally. Over the 1 month, the diurnal middepth temperature fluctuations (Fig. 3d) were coherent at a level of $\approx 0.8$ between the three alongshore temperature moorings (i.e., $\mathrm{Tr}, \mathrm{W} 1$, and $\mathrm{W} 2$ ), with a northto-south phase propagation of approximately $40 \mathrm{~cm} \mathrm{~s}^{-1}$ (see Fig. 3d). The IS stratification (not shown) was dominated by the vertical temperature gradient, where the average temperature difference was $2.1^{\circ} \mathrm{C}$ over a vertical distance of $7.5 \mathrm{~m}$ (not shown). During R2, the middepth temperature varied by $1.5^{\circ} \mathrm{C}$, and the dye release (magenta, Fig. 3) occurred during the cooling phase of the DIT. Subinertial, diurnal internal waves have previously been observed in the Southern California Bight region (e.g., Nam and Send 2011; Kumar et al. 2016). A diurnal sea breeze can force diurnal band internal oscillations (e.g., Walter et al. 2017) that are potentially resonant if the effective inertial frequency is decreased due to shear in subtidal alongshore currents (e.g., Lerczak et al. 2001). 

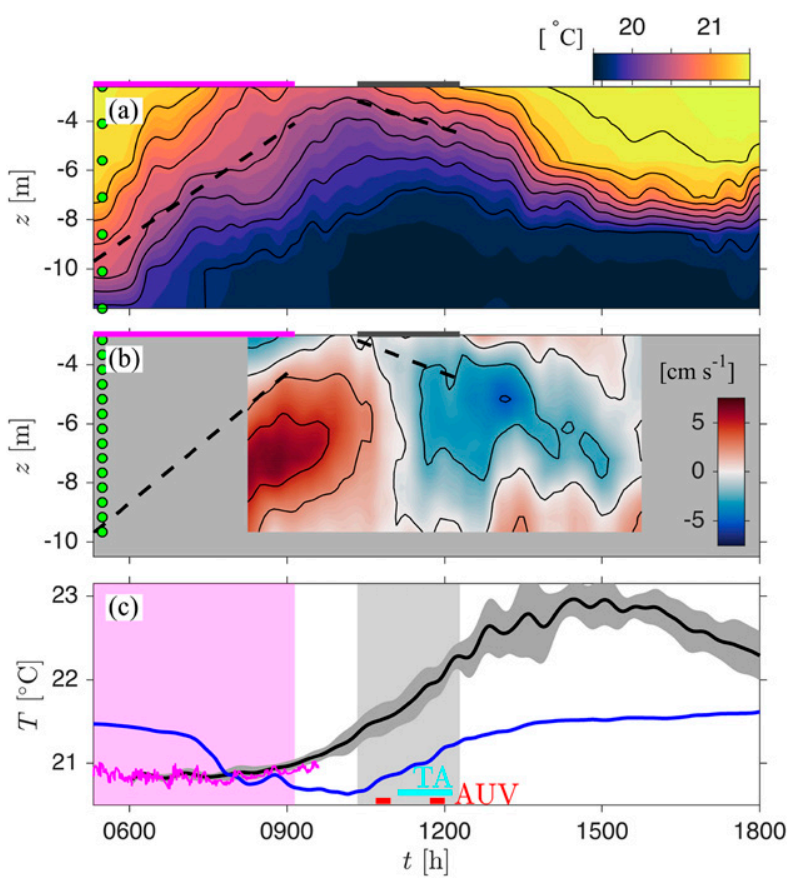

FIG. 4. Large-scale (a) temperature $\bar{T}$ at mooring $\operatorname{Tr}$ (white cross in Figs. 1 and 2-6) with contours at $0.25^{\circ} \mathrm{C}$ intervals and (b) crossshore velocity $\bar{u}$ at ADCP (white diamond in Figs. 1 and 6) adjacent to $\mathrm{Tr}$, with contours at $2.5 \mathrm{~cm} \mathrm{~s}^{-1}$ intervals. In (a) and (b) green dots indicate approximate instrument sample depths, and the dashed black lines are average $\bar{T}=20.5^{\circ} \mathrm{C}$ isotherm slopes of 1.5 and $-0.7 \mathrm{~m} \mathrm{~h}^{-1}$ during the release (magenta bar, top) and deformation (gray bar, top) periods, respectively. (c) Raw temperature vs time at the release location (magenta), with low-pass-filtered upper $\operatorname{Tr}$ thermistor $(z=-2.6 \mathrm{~m}$, blue); and temperature derived from the large-scale-filtered and alongshore average SZ instruments (black curve) \pm the 30 -min running rms deviation from the mean (gray shading). In (c) the AUV (red) and TA (cyan) transect times are indicated by horizontal bars.

On the day of R2, the DIT both shoaled and relaxed isotherms at mooring $\operatorname{Tr}(h=12 \mathrm{~m}$, Fig. 4a). Over the release period (magenta bar, top of Fig. 4a) the $T=$ $20.5^{\circ} \mathrm{C}$ isotherm shoaled $5.5 \mathrm{~m}$ over $3 \mathrm{~h}$ (dashed black line in Fig. 4a). Subsequently, the water column warmed, with the $T=20.5^{\circ} \mathrm{C}$ isotherm deepening about $0.6 \mathrm{~m}$ over $2 \mathrm{~h}$ (termed deformation period; gray bar, top of Fig. 4a). The rapid cooling then warming at $\mathrm{Tr}$ was associated with a large-scale baroclinic cross-shore velocity observed at ADCP that delivered cold water onshore at depth prior to and during the release period and reversed during the deformation period (Fig. 4b). This large-scale temperature fluctuation and velocity signature was observed at all three moorings (Tr, W1, W2). Thermally driven exchange has diurnal temperature and cross-shore flow signals (Molina et al. 2014), however it does not set up an alongshore propagating wave motion (Fig. 3d) nor does it have the observed mode- 1 structure and phasing
(Fig. 4b), thus is not a likely mechanism for the observed diurnal signal.

The large-scale $(>30 \mathrm{~min})$ and alongshore averaged SZ temperature, estimated from 9 thermistors spanning $7 \mathrm{~km}$ alongshore (R2, S1-S3, and M1-M5 in Fig. 1), was dominated by the diurnal heating/cooling cycle (Fig. 4c). The SZ root-mean-square (rms) deviations from the alongshore average (gray shading, Fig. $4 \mathrm{c})$ were small $\left(<0.2^{\circ} \mathrm{C}\right)$ prior to the deformation period. During the first half of the release period, the $\mathrm{R} 2$ location temperature ( $T_{\text {rel }}$, magenta in Fig. $4 \mathrm{c}$ ) was on average $\approx 0.5^{\circ} \mathrm{C}$ colder than the Tr mooring $z=-2.7 \mathrm{~m}$ thermistor (blue, Fig. 4c). This is likely a lower bound for the cross-shore temperature difference between the SZ and Tr, because for a well-mixed SZ with an average depth of $1 \mathrm{~m}$, a thermistor at this $z$ level for a stably stratified IS would likely be warmer than that observed at $z=-2.7 \mathrm{~m}$. By $0800 \mathrm{~h}$, the SZ was rapidly warming from solar radiation, whereas the IS temperature dropped as the DIT approached its maximum cold phase at approximately $1000 \mathrm{~h}$. Thus, alongshore gradients were weak relative to the $0.5^{\circ} \mathrm{C}$ cross-shore difference.

\section{b. General tracer observations}

By $1020 \mathrm{~h}\left(t_{r}=5.02 \mathrm{~h}\right)$, the beginning of the deformation period, the dye plume extended approximately $4 \mathrm{~km}$ alongshore (Fig. 5a). The northern portion of the dye plume ( $y>2.5 \mathrm{~km}$, denoted SZ plume) was narrow $\left(<200 \mathrm{~m}\right.$, or $\left.<2 L_{\mathrm{sz}}\right)$ and shoreline attached with northward tracer transport over the day (Figs. 5a-c), consistent with SZ currents driven by obliquely incident south swell (Longuet-Higgins 1970a,b). In contrast, at the same time the southern portion of the plume $(y<2 \mathrm{~km}$, hereafter the IS plume) was up to $800 \mathrm{~m}$ (or $8 L_{\mathrm{sz}}$ ) wide, extending into almost $h=12-\mathrm{m}$ depth and was shoreline detached to the south $(y<400 \mathrm{~m})$. This implies that some transport mechanism brought the SZ released tracer out to $8 L_{\mathrm{sz}}$ over $3-5 \mathrm{~h}$. Between 1020 and $1230 \mathrm{~h}$ (denoted deformation period, gray bar in Figs. 3 and 4) tracer in the IS plume deformed onshore to $5 L_{\mathrm{sz}}$ and was transported south, while a dye free SZ intrusion advected from the south, further detaching the IS plume from the shoreline (Figs. 5a-c). The northward advection of the SZ plume and the southward advection of the IS plume resulted in a 9-km alongshore extent by $1658 \mathrm{~h}$ $\left(t_{r}=11.65 \mathrm{~h}\right)$. At this time $(\approx 6.5 \mathrm{~h}$ after the deformation period ended), the plume still remained within $8 L_{\mathrm{sz}}$ from shore at the surface (Fig. 5d). Here, we focus on the deformation period evolution of the IS plume.

\section{c. Deformation period large-scale inner-shelf plume evolution}

During the deformation period (gray bar in Fig. 3), the offshore plume boundary (thick black $\bar{D}=1 \mathrm{ppb}$ contour 


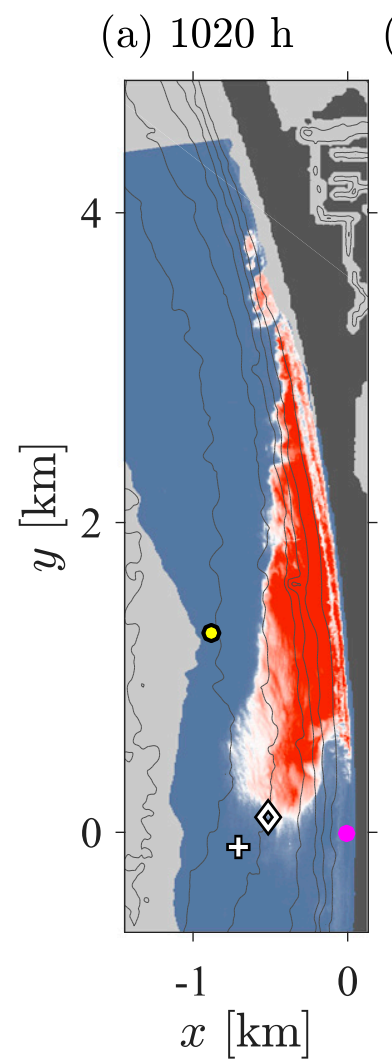

(b) $1049 \mathrm{~h}$

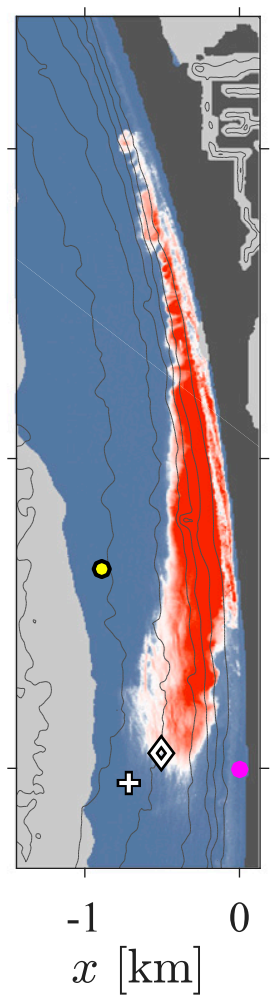

(c) $1155 \mathrm{~h}$

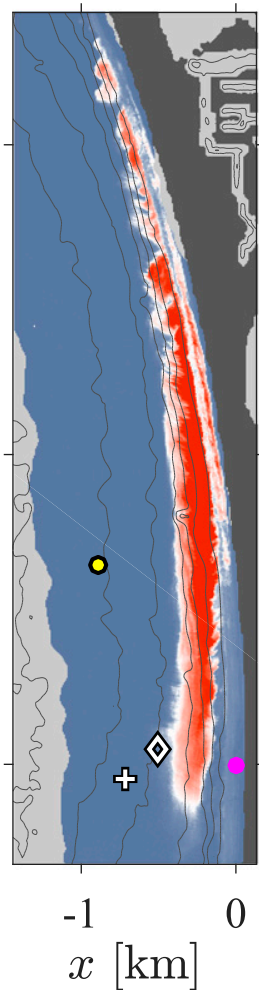

(d) $1658 \mathrm{~h}$

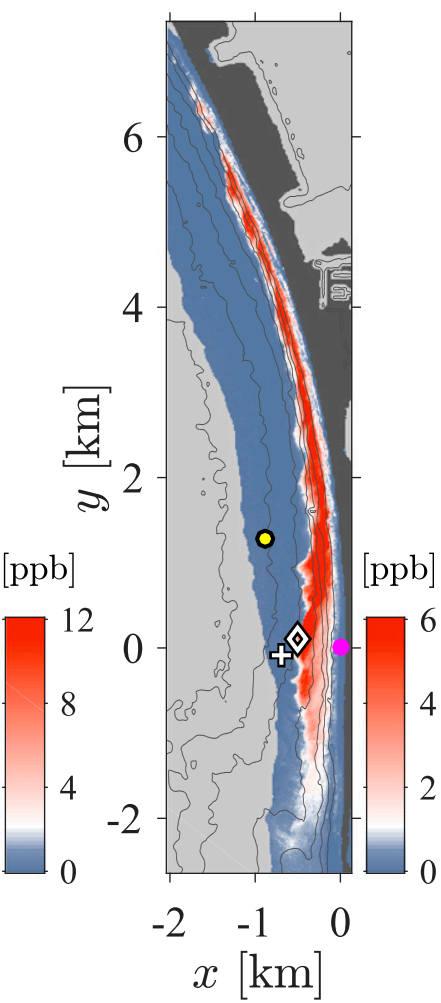

FIG. 5. Surface dye concentration $D$ vs horizontal coordinates $(x, y)$ during (a)-(c) deformation period and $(\mathrm{d}) \approx 12 \mathrm{~h}$ after dye release began. Time is indicated above each panel in hhmm relative to Pacific daylight time $\left(\right.$ PDT $\rightarrow \mathrm{h}$ ), corresponding to $t_{r}=[5.02,5.50,6.60,11.65] \mathrm{h}$, respectively. Note the difference in scales in (d). Release location (magenta dot), IS temperature mooring $\operatorname{Tr}$ (cross), current meter ADCP (diamond), and Wirewalker W1 (yellow) are indicated. Land is dark gray, oceanic regions without data are light gray, and bathymetry contours (black) are drawn at 2-m intervals below mean sea level.

in Fig. 6) propagated onshore at up to $5 \mathrm{~cm} \mathrm{~s}^{-1}$, deforming the plume. Concurrently, the IS plume elongated alongshore with the southern front moving past the release point at approximately $7 \mathrm{~cm} \mathrm{~s}^{-1}$. Meanwhile, a dye free region within the SZ moved north at a similar rate, detaching the IS plume from shore (dark gray in Fig. 6).

The large-scale vertical and cross-shore structure of the IS temperature and plume deformation can be seen along the AUV transect $(y=395$, dashed red line in Fig. 6). Toward the beginning of the deformation period at $1049 \mathrm{~h}$ (first red bar, Fig. 4c), the IS plume was surface trapped $(\tilde{z} \geq-3 \mathrm{~m})$ and extended offshore of $\tilde{x}=-700 \mathrm{~m}$ (Fig. 7a), with isotherms sloping upward toward shore (e.g., $\bar{T}=20.5^{\circ} \mathrm{C}$ isotherm slope, dashed in Fig. $7 \mathrm{c}$ ). At this time, the $\mathrm{SZ}$ temperature was $\approx 21.75^{\circ} \mathrm{C}$, about $0.25^{\circ} \mathrm{C}$ greater than the maximum observed AUV temperature, indicating that the isotherm slope changed sign between the SZ and $\tilde{x}=-400 \mathrm{~m}$ ( or $\approx 4 L_{\mathrm{sz}}$ ). Additionally, the dye plume was largely confined to $T \geq 20.25^{\circ} \mathrm{C}$, about $0.45^{\circ} \mathrm{C}$ below the minimum of $T_{\text {rel }}$ (magenta,
Fig. 4c), indicating mixing with colder water prior to the deformation period.

Consistent with the aerial dye observations (Fig. 6), later in the deformation period at $1151 \mathrm{~h}$ (second red bar, Fig. 4c), the offshore dye front moved onshore to $\tilde{x} \approx-500 \mathrm{~m}$ (Fig. $7 \mathrm{~b})$ and deepened $(\tilde{z} \geq-6 \mathrm{~m})$. At this time, the AUV $\bar{T}=20.5^{\circ} \mathrm{C}$ isotherm deepened, consistent with the deepening $\mathrm{Tr}$ isotherms (dashed line below gray bar in Fig. 4a) and the isotherm slope changed sign (sloping upward offshore). The deepening AUV isotherms and dye plume suggest that the cross-shore plume narrowing was partially balanced by vertical thickening. The observed relaxation of the cross-shore temperature gradient over the deformation period is also consistent with baroclinic flow associated with the DIT (Fig. 4b).

Deformation period warming and IS plume deepening were also observed along TA transect $(\tilde{x} \approx-350 \mathrm{~m}$ and $h \approx 6.5 \mathrm{~m}$, cyan in Figs. 1 and 6 ), which captures both alongshore and temporal variations in the large-scale temperature and dye fields. Between 1107 and $1208 \mathrm{~h}$ (cyan bar, Fig. 4 c; and $0.54 \lesssim y \lesssim 2.7$ km, Fig. 8 ) the TA 
(a) $1020 \mathrm{~h}$

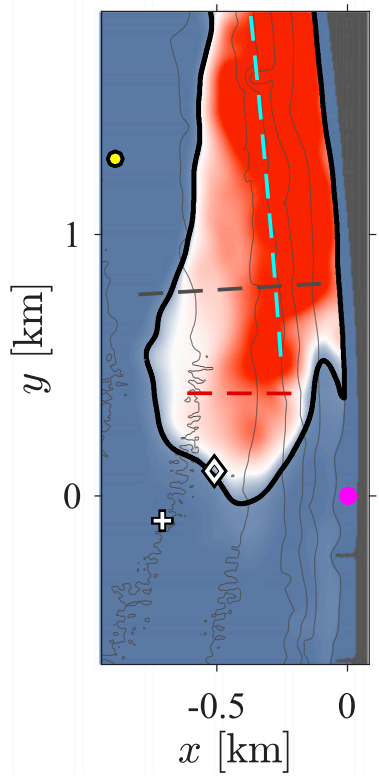

(b) $1054 \mathrm{~h}$

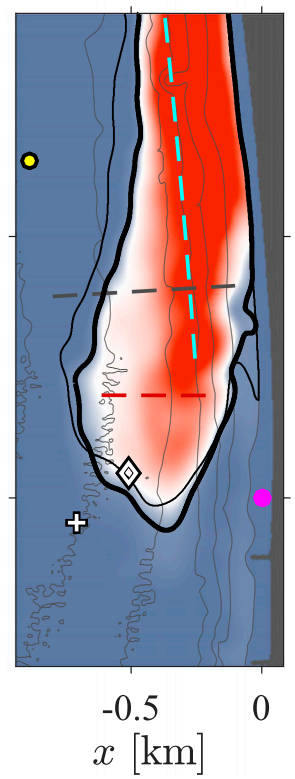

(c) $1124 \mathrm{~h}$

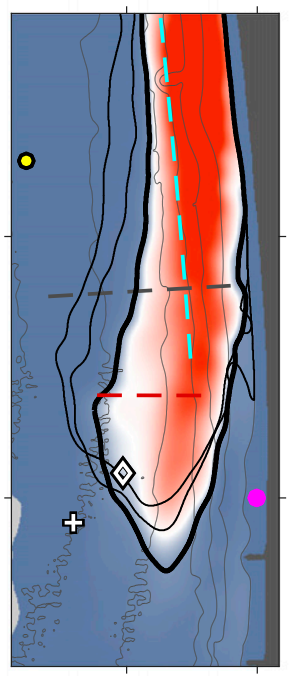

$-0.5 \quad 0$

$x[\mathrm{~km}]$ (d) $1204 \mathrm{~h}$

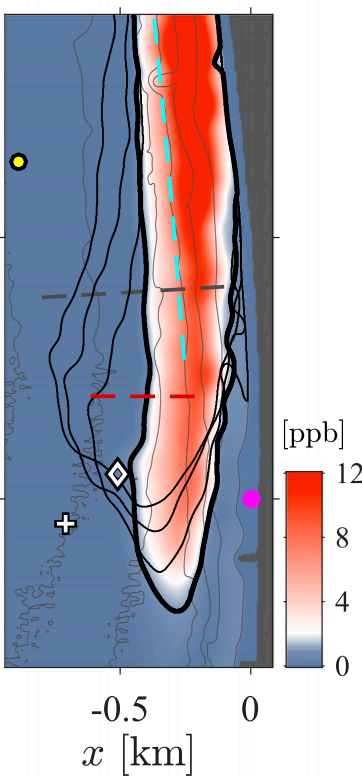

FIG. 6. (a)-(d) Large-scale IS surface dye $\bar{D}$ evolution during deformation period vs $x$ and $y$. In each panel time is relative to PDT, corresponding to $t_{r}=[5.02,5.59,6.09,6.75] \mathrm{h}$, respectively. The 1 -ppb contour (thick black) at each time along with all prior contours (thin black) is shown to indicate deformation. The magenta dot $(x, y)=(0,0)$ is the release location. Also drawn are the average locations of the AUV transect (dashed red line), alongshore TA transect (dashed cyan line), and the gray dashed line is the MASS transect. Dark gray indicates land and the bathymetry is contoured at 2-m intervals below mean sea level.

temperature increased with time (or $y$ ) at all depths, with the greatest increase of $\approx 1^{\circ} \mathrm{C}$ below $\tilde{z}=-5 \mathrm{~m}$. The isotherms sloped downward roughly $1.2 \mathrm{~m} \mathrm{~km}^{-1}$ or $2.82 \mathrm{~m} \mathrm{~h}^{-1}$ relative to space or time, respectively.
The TA dye plume deepened at a rate similar to the isotherms and eventually detached from the surface (Fig. 8b). Initially, at $y=0.54 \mathrm{~km}(1107 \mathrm{~h})$ the dye was confined to $\tilde{z}>-4 \mathrm{~m}$ (Fig. $8 \mathrm{~b}$ ) and the $\bar{T}=20.5^{\circ} \mathrm{C}$
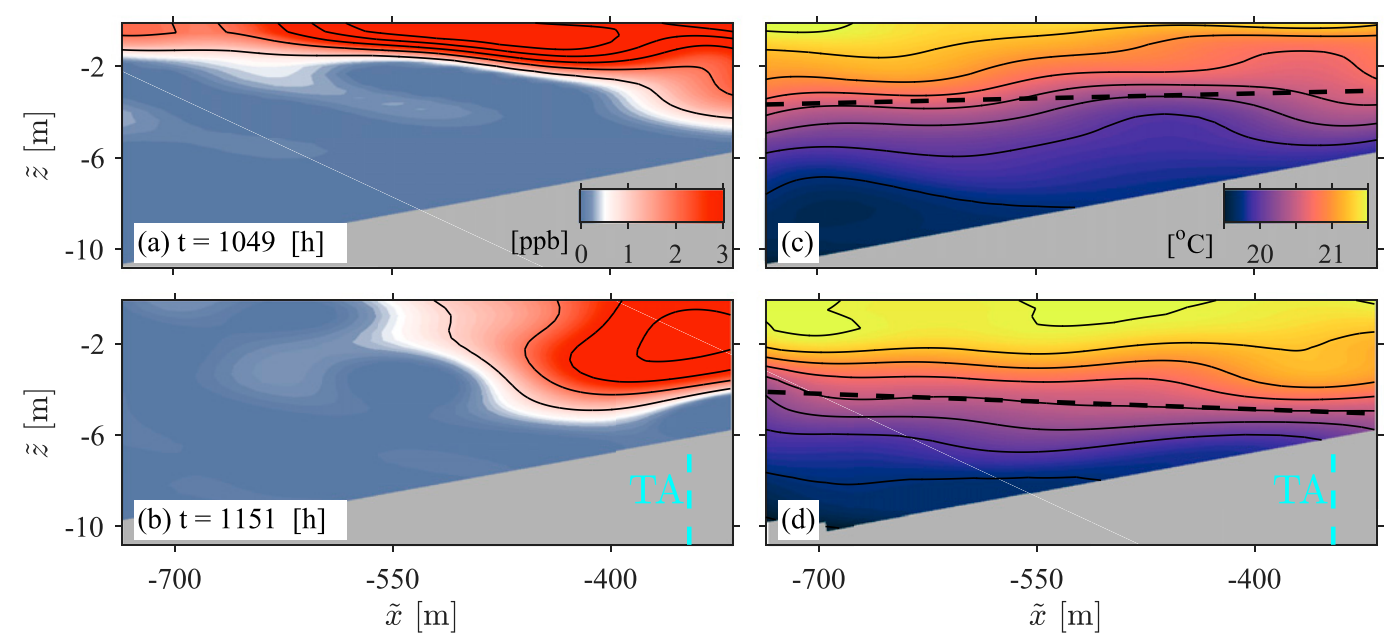

FIG. 7. (left) AUV transect large-scale dye concentration $\bar{D}$ with contours at 1-ppb intervals and (right) temperature $\bar{T}$ with contours at $0.25^{\circ} \mathrm{C}$ intervals vs local cross-shore coordinate $\tilde{x}$ and vertical coordinate $\tilde{z}$ at (a), (c) $t=$ $1049 \mathrm{~h}\left(t_{r}=5.50 \mathrm{~h}\right)$ and $(\mathrm{b}),(\mathrm{d}) t=1151 \mathrm{~h}\left(t_{r}=6.54 \mathrm{~h}\right)$. The AUV transect line is shown as red dashed line in Fig. 6 , and each transect took approximately $20 \mathrm{~min}$. In (c) and (d) the dashed lines are the average $T=20.5^{\circ} \mathrm{C}$ isotherm slopes with values of $1.44 \mathrm{~m} \mathrm{~km}^{-1}$ in (c) and $-2.3 \mathrm{~m} \mathrm{~km}^{-1}$ in (d). The approximate cross-shore location of TA (cyan, Fig. 8) is indicated in (b) and (d). 


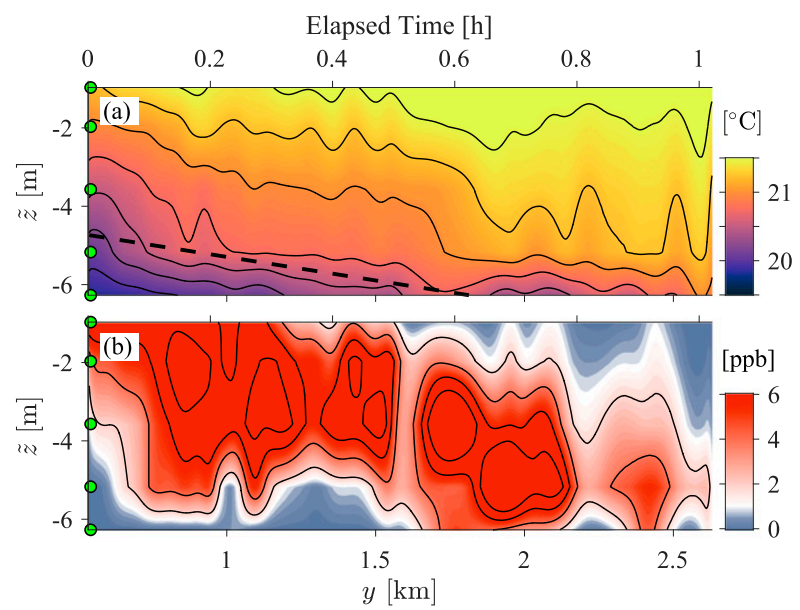

FIG. 8. TA transect large-scale (a) temperature $\bar{T}$ with contours at $0.25^{\circ} \mathrm{C}$ and (b) dye $\bar{D}$ with contours at $2 \mathrm{ppb}$ vs depth $\tilde{z}$ and alongshore coordinate $y$. TA transect line is shown in Figs. $1 \mathrm{a}$ and 6. The transect began at $t=1107 \mathrm{~h}\left(t_{r}=5.80 \mathrm{~h}\right)$, and the elapsed time is marked on top. Instrument locations are indicated by green circles on the left axis, and the black dashed line in (a) is the slope of the $\bar{T}=20.5^{\circ} \mathrm{C}$ contour, $-1.20 \mathrm{~m} \mathrm{~km}^{-1}$ or $-2.82 \mathrm{~m} \mathrm{~h}^{-1}$.

isotherm was at roughly $\tilde{z}=-4.5 \mathrm{~m}$. The dye reached $\tilde{z}=-6 \mathrm{~m}$ by about $y=0.8 \mathrm{~km}$ (or $1115 \mathrm{~h}$ ), and by $y=$ $1.5 \mathrm{~km}$ dye was capped by a warmer $>25.5^{\circ} \mathrm{C}$ layer. The dye then remained subsurface as the TA extended north, beyond the IS plume region (i.e., $y>2 \mathrm{~km}$ ). Similar to AUV, the dye was largely confined to $20.25^{\circ} \leq \bar{T} \leq 21.5^{\circ} \mathrm{C}$ as both isotherms and iso-dye deepened.

\section{d. Release and deformation period statistical plume evolution}

To examine temporal evolution of joint $(D, T)$ statistics and evaluate the role of mixing in observed IS plume evolution, arithmetic temperature and logarithmic dye means and standard deviations were calculated over 3-4 approximately 44-min time intervals from all raw (i.e., unfiltered and not interpolated) SZ, AUV, and TA observations where $D \geq 1 \mathrm{ppb}$. The average SZ plume (predominantly from instruments S2-S3 and M1-M4 in Fig. 1) temperature increased $>1^{\circ} \mathrm{C}$ from 0942 to $1154 \mathrm{~h}$ due to solar heating. The standard deviation of SZ plume temperature also increased with time from approximately $0.1^{\circ}$ to $0.25^{\circ} \mathrm{C}$ (horizontal black dotted lines, Fig. 9) due to an increase in SZ temperature anomalies during the deformation period (gray shading, Fig. 4c). Meanwhile, average SZ dye concentration decreased by an order of magnitude, with the standard deviation in concentration (vertical black dotted lines, Fig. 9) increasing. The large standard deviation in SZ plume dye concentration at $t=$ $1025 \mathrm{~h}$ was due to an $\approx 30$-ppb concentration difference between instruments M1 and M2 and instruments S2, S3, and M3 (see Fig. 1b). The SZ plume joint dye/temperature

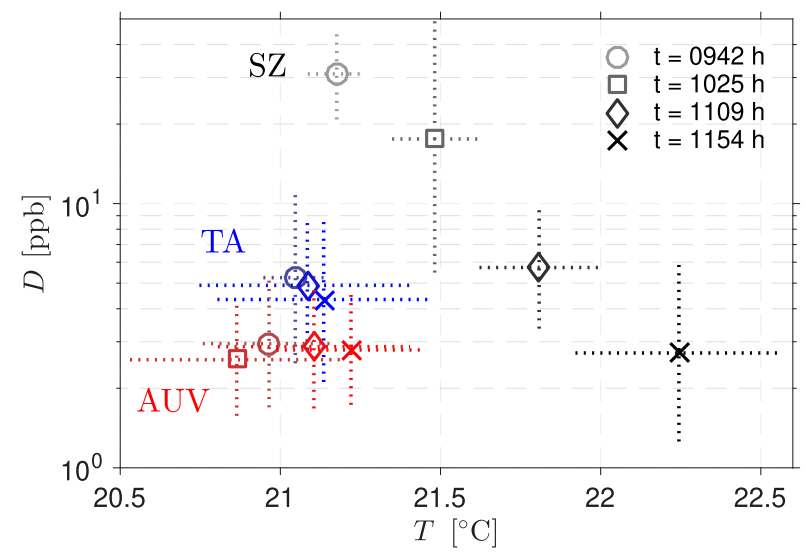

FIG. 9. Dye vs temperature and time on morning of $\mathrm{R} 2$ from the SZ (black), at TA (blue), and AUV (red). Thick markers represent arithmetic mean temperature (i.e., $E[T]$, where $E[]$ is the averaging operator) and logarithmic mean dye (i.e., $\exp \{E[\log (D)]\})$ of observations where $D \geq 1 \mathrm{ppb}$, evaluated at approximately 44-min intervals $\left(t_{r}=[4.39,5.10,5.84,6.59] \mathrm{h}\right)$, and the dashes represent \pm 1 standard deviation over the same interval. TA and AUV transect data from $0942 \mathrm{~h}\left(t_{r}=4.39 \mathrm{~h}\right.$, red and blue circles) prior the deformation period and before aerial sampling began are included here for comparison with SZ observations.

evolution indicates a fast response to solar forcing and vigorous lateral mixing.

In contrast, the IS plume joint dye and temperature statistics were relatively stable in time. The average observed temperature of the IS dye plume increased slightly $\left(\approx 0.25^{\circ} \mathrm{C}\right)$ during the deformation period (Fig. 9), less than half that of the SZ plume, consistent with a depthdependent response to solar heating. The standard deviation of temperature in the IS plume (i.e., at both TA and AUV) remained roughly $0.25^{\circ} \mathrm{C}$ throughout the deformation. The IS plume dye concentration was much lower than the SZ and did not decrease considerably over the morning, varying between 2.5 and $6 \mathrm{ppb}$, with a standard deviation around $1.8 \mathrm{ppb}$ (red and blue vertical dotted lines in Fig. 9). The broader $t=0942 \mathrm{~h}$ temperature distribution on the IS illustrates that the IS plume was vertically stratified prior to deformation. The consistent IS plume temperature span and dye concentration suggests vertical mixing was not responsible for the observed IS plume deepening during the deformation period.

\section{e. Large-scale cross-shore convergence and alongshore elongation of inner-shelf plume}

The deformation period MASS surface dye and temperature measurements suggest that the IS plume narrowing and elongation (Fig. 6) was largely driven by advection. Here measurements are examined on a crossshore line at $y=818 \mathrm{~m}$ within the IS plume (gray dashed line Fig. 6). Prior to deformation at 1020 h, the offshore 


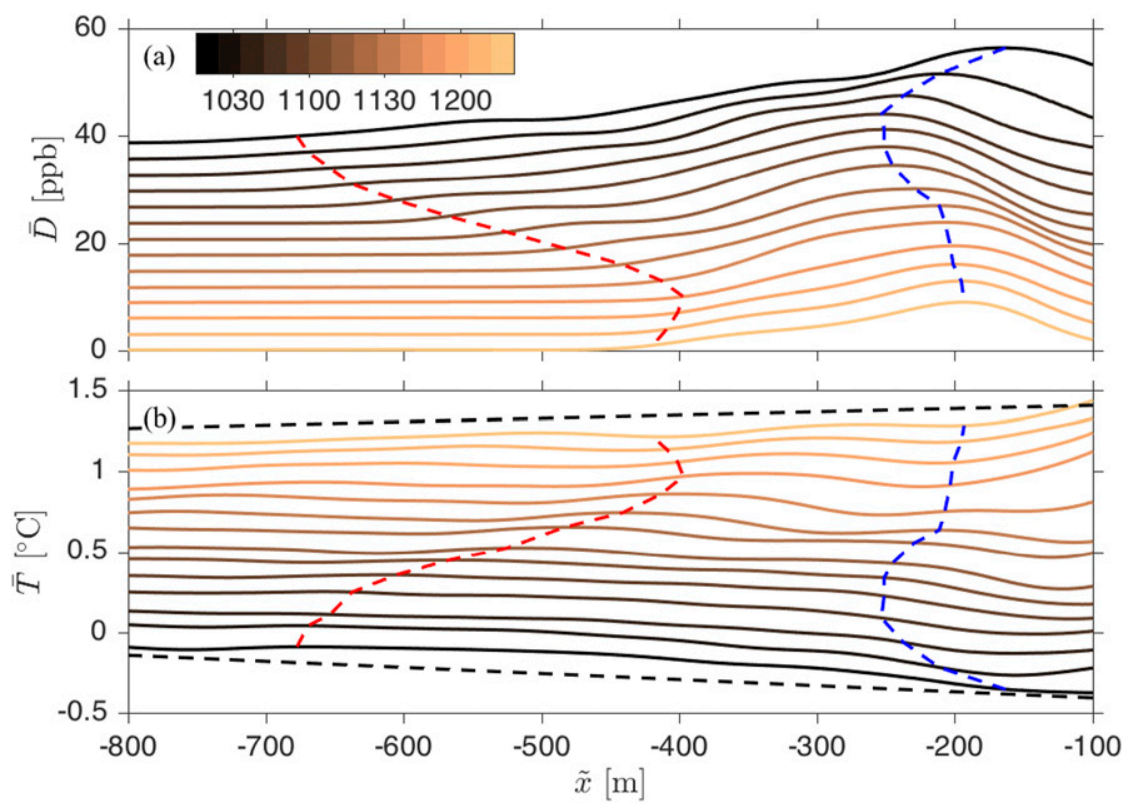

FIG. 10. Surface (a) dye concentration and (b) relative temperature vs local cross-shore coordinate $\tilde{x}$ at multiple times [see colorbar in (a)] during the deformation period. In (a) the surface dye concentration [measured in parts per billion (ppb)] of each curve is offset by $-3 \mathrm{ppb}$ (earliest observation is the uppermost curve); in (b) the surface temperature is relative to $1 \mathrm{~km}$ offshore and each curve is offset by $0.1^{\circ} \mathrm{C}$; and in (a) and (b) the red dashed curve is the offshore location of $\bar{D}=1 \mathrm{ppb}$ (see black contour in Fig. 6), and the blue dashed curve is the location of $\bar{D}_{\max }$. The dashed black lines have $\partial \bar{T} / \partial \tilde{x}=-0.38^{\circ}$ and $0.2^{\circ} \mathrm{C} \mathrm{km}^{-1}$ between $\tilde{x}=-800$ and $-100 \mathrm{~m}$ and correspond to $t=1020$ and $1217 \mathrm{~h}$, respectively.

$\bar{D}=1 \mathrm{ppb}$ contour (Fig. 6a) was roughly $700 \mathrm{~m}$ from shore on the MASS cross-shore line. At this time, there was an IS surface temperature gradient $\partial \bar{T} / \partial \tilde{x}$ (calculated between $\tilde{x}=-800$ and $-100 \mathrm{~m}$ ) of $-0.38^{\circ} \mathrm{C} \mathrm{km}^{-1}$ (i.e., colder onshore, lower black curve, Fig. 10b). Between 1020 and $1137 \mathrm{~h}$ the $\bar{D}=1 \mathrm{ppb}$ front (red dashed line, Fig. 10a) moved onshore about $275 \mathrm{~m}$, and remained $<500 \mathrm{~m}$ offshore until $1217 \mathrm{~h}$ (lower yellow curve, Fig. 10a). The onshore speed $u_{f}$ was approximately $5 \mathrm{~cm} \mathrm{~s}^{-1}$ and was estimated as, $u_{f}=\Delta x_{f} / \Delta t+$ $v\left(\delta x_{f} / \delta y_{f}\right)$, where $\Delta x_{f} / \Delta t$ is the shoreward progression of the $\bar{D}=1 \mathrm{ppb}$ contour along the MASS line and $v\left(\delta x_{f} / \delta y_{f}\right)$ accounts for the southward advection of the sloped contour where it intersects the MASS line. Meanwhile, the MASS cross-shore temperature gradient continuously increased, switching sign, and reaching approximately $0.2^{\circ} \mathrm{C} \mathrm{km}^{-1}$ at $1217 \mathrm{~h}$, consistent with the relaxation of shoaled isotherms observed at $\operatorname{Tr}$ (Fig. 4a) and the reversal of the cross-shore temperature gradient at AUV (Figs. 7c,d).

In contrast to the onshore progression of the $\bar{D}=1 \mathrm{ppb}$ contour, between 1020 and $1036 \mathrm{~h}$ the cross-shore location of the peak dye concentration $\bar{D}_{\text {max }}$ (blue dashed Fig. 10a) moved offshore $\approx 100 \mathrm{~m}$ to $\tilde{x} \approx-250 \mathrm{~m}$, as the dye-free intrusion progressed north in the $\mathrm{SZ}$ and crossed the MASS transect (see Figs. 6a,b). The dye maximum then moved onshore $\approx 60 \mathrm{~m}$ at roughly $1 \mathrm{~cm} \mathrm{~s}^{-1}$. Additionally, the $\bar{D}_{\max }$ decrease in time was relatively small. As such, the average $\partial \bar{D} / \partial \tilde{x}$, calculated as the slope of $\bar{D}(x)$ between $\bar{D}=1 \mathrm{ppb}$ and $\bar{D}_{\max }$ (i.e., red and blue curves in Fig. 10a), increased from $28 \mathrm{ppb} \mathrm{km}^{-1}$ at $1020 \mathrm{~h}$ to $66 \mathrm{ppb} \mathrm{km}^{-1}$ at $1137 \mathrm{~h}$ (not shown). The steepening offshore dye gradient indicates convergent onshore advection (consistent with the DIT) as opposed to a diffusive advancement of the $\bar{D}=1 \mathrm{ppb}$ contour, which would require an upgradient diffusive flux and an inferred negative cross-shore diffusivity between -8 and $-2 \mathrm{~m}^{2} \mathrm{~s}^{-1}$. Thus, shoreward advancement of the $\bar{D}=1 \mathrm{ppb}$ contour was largely due to advection.

Coincident with the cross-shore deformation, the IS plume elongated (strained) in the alongshore direction (Figs. 6 and 7). This elongation is also evident in the alongshore $y$ evolution of the cross-shore maximum dye concentration $\bar{D}_{\max }(y)$ (Fig. 11). At $1020 \mathrm{~h}$ (black curve, Fig. 11) the southern edge of the IS plume was just north of the release location ( $y=0$ in Figs. 6 and 11) and farther to the north there were several prominent $\approx 5$-ppb magnitude and $\approx 250$-m-wide features (e.g., tail of arrows in Fig. 11). Between 1020 and $1217 \mathrm{~h}$ the southern dye front advected southward at $\approx 6.5 \mathrm{~cm} \mathrm{~s}^{-1}$, approaching 


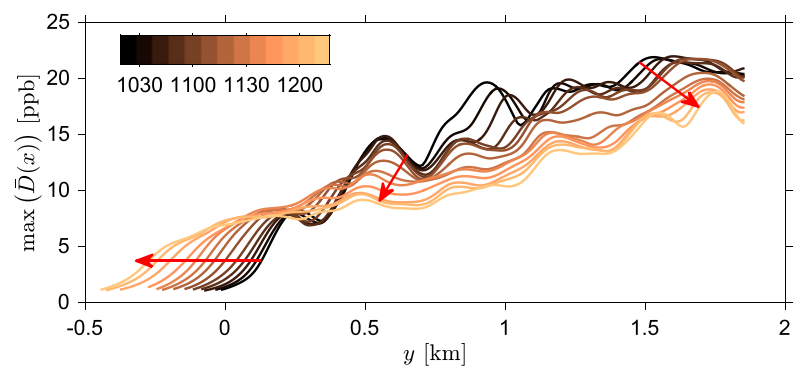

FIG. 11. Cross-shore maximum of the mean surface dye concentration $\bar{D}$ vs $y$ during the deformation period, where the color of each curve indicates time of observation shown in the legend, red arrows indicate (from left to right) $-6.5,-1.5$, and $3 \mathrm{~cm} \mathrm{~s}^{-1}$, illustrating an alongshore plume strain rate of approximately $5 \mathrm{~cm} \mathrm{~s}^{-1} \mathrm{~km}^{-1}$.

$y=-500 \mathrm{~m}$ (left arrow, Fig. 11). Coherent $D_{\max }$ features at $y \leq 750 \mathrm{~m}$ also propagated to the south at $\approx 1.5 \mathrm{~cm} \mathrm{~s}^{-1}$ (middle arrow, Fig. 11). At $y \approx 1.5 \mathrm{~km}$, features advected northward at $\approx 3 \mathrm{~cm} \mathrm{~s}^{-1}$ (right arrow, Fig. 11). The differential advection of plume features implies an average alongshore plume straining of $4.5 \mathrm{~cm} \mathrm{~s}^{-1} \mathrm{~km}^{-1}$.

The IS plume centerline (cross-shore position of $\bar{D}_{\max }$ ) was tilted slightly from shore parallel south of MASS transect (Fig. 6), resulting in some aliasing of cross-shore sheared alongshore transport into observed elongation. The bathymetry also varies slightly alongshore (Fig. 6). However, the alongshore elongation apparent in $D_{\max }$ (Fig. 11) is also apparent using $\bar{D}$ at a fixed cross-shore distance (e.g., 200-400 m) or along a given bathymetry contour (e.g., 4-8 m), yielding similar strain rates. This suggests that potential aliasing due to cross-shore plume structure was weak. During the deformation period, the IS plume centerline tilt (relative to the shoreline) south of the MASS transect decreased from 0.15 to 0.05 (not shown) predominantly due to the onshore advection of $\bar{D}_{\max }$, rather than due to the southward propagating front. Combined with the presence of straining between $\bar{D}_{\text {max }}$ features north of MASS transect $(y>800 \mathrm{~m}$, Fig. 11), where the centerline was nearly shore parallel, indicates that the alongshore plume elongation was not driven by alongshore uniform shear, that is, $\partial v / \partial x$.

\section{f. Small-scale and high-frequency inner-shelf plume evolution}

In addition to large-scale dye $\bar{D}$ and temperature $\bar{T}$, the small-scale $D^{\prime}$ and $T^{\prime}$ fields had rich structure and evolution (e.g., $D^{\prime}$ in Fig. 2c). At mooring Tr, high frequency (HF, see section $2 \mathrm{~d}$ ) temperature fluctuations were approximately $\pm 0.25^{\circ} \mathrm{C}$ with time scales of roughly $10 \mathrm{~min}$ (Fig. 12), longer than the depth- and timeaveraged buoyancy period of roughly $4.5 \mathrm{~min}$. HF IW fluctuations with similar time scale were observed at ADCP with $u^{\prime}$ magnitude of $\approx 1 \mathrm{~cm} \mathrm{~s}^{-1}$ (not shown).

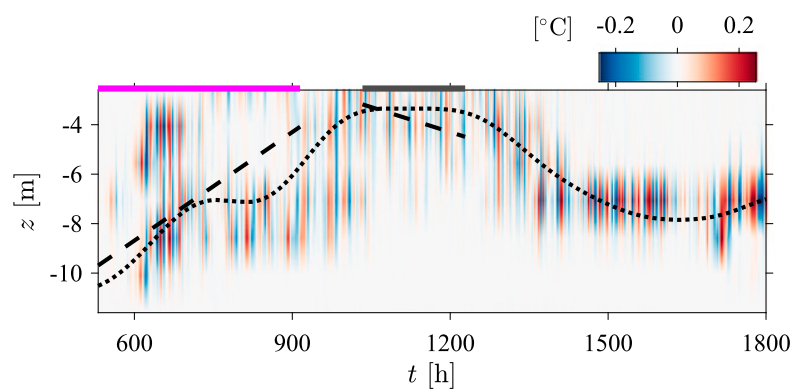

FIG. 12. Small-scale temperature $T^{\prime}$ at thermistor string $\operatorname{Tr}$ (white cross in Figs. 1 and 2-6) as a function of depth and time. The horizontal magenta, and gray bars span the release and deformation periods, respectively, and the dashed black line is the average slope of the $\bar{T}=20.5^{\circ} \mathrm{C}$ isotherm (see Fig. 4). The dotted black line is the 3-h large-scale filtered vertical location of maximum temperature stratification.

The $T^{\prime}$ fluctuations were near-surface intensified [i.e., the maximum $T^{\prime}(z)$ was at $z \geq-6 \mathrm{~m}$ ] just prior to and throughout the deformation period, coincident with the maximum of the DIT cold phase (Fig. 12). Largest $T^{\prime}$ fluctuations occurred near the depth of the maximum 3-h large-scale filtered vertical temperature gradient (dotted line in Fig. 12) as expected from WKB theory (e.g., Hendershott 1981), indicating that the largescale DIT modulated the vertical structure of the HF IWs, potentially enabling HF IWs to propagate into shallower water and contribute to nearshore mixing and exchange. HF IWs are often linked to internal tides (e.g., Zhang et al. 2015).

The signature of HF IWs is also evident in small scale surface temperature and dye fields (Fig. 13). HF IWs have been observed previously via aerial LWIR (e.g., Walsh et al. 1998; Marmorino et al. 2004) with the surface $T^{\prime}$ signal attributed to IW modulation of the surface thermal layer (Farrar et al. 2007). The surface IW dye signal is likely the result of IW horizontal convergence (divergence) that thickened (thinned) the near-surface plume, slightly altering the remotely sensed concentration (e.g., Fig. 2c). The cross-shore gradient $\left(\partial D^{\prime} / \partial x\right.$ and $\partial T^{\prime} / \partial x$ ) further highlights the small-scale features (Fig. 13). For example, at $t=1155 \mathrm{~h}$, a packet of HF IW intersected the MASS transect (gray dashed line in Fig. 13) at $\tilde{x} \approx-200 \mathrm{~m}$ and within the IS plume. The packet was roughly alongshore oriented and extended between $200 \leqq y \leqq 1500 \mathrm{~m}$ in $\partial T^{\prime} / \partial x$ (Fig. 13b). This feature is also present in the $\partial D^{\prime} / \partial x$ field for $500<y<$ $1500 \mathrm{~m}$ (Fig. 13a). Other, somewhat weaker, small-scale $\partial T^{\prime} / \partial x$ features are present outside the plume, but not in the $\partial D^{\prime} / \partial x$ field as $D=0$. Onshore of $\tilde{x}=-250 \mathrm{~m}$, the signature of rip currents are also present in $D^{\prime}$ and $T^{\prime}$, where features have significantly shorter $(\approx 100 \mathrm{~m})$ alongshore length scales. 

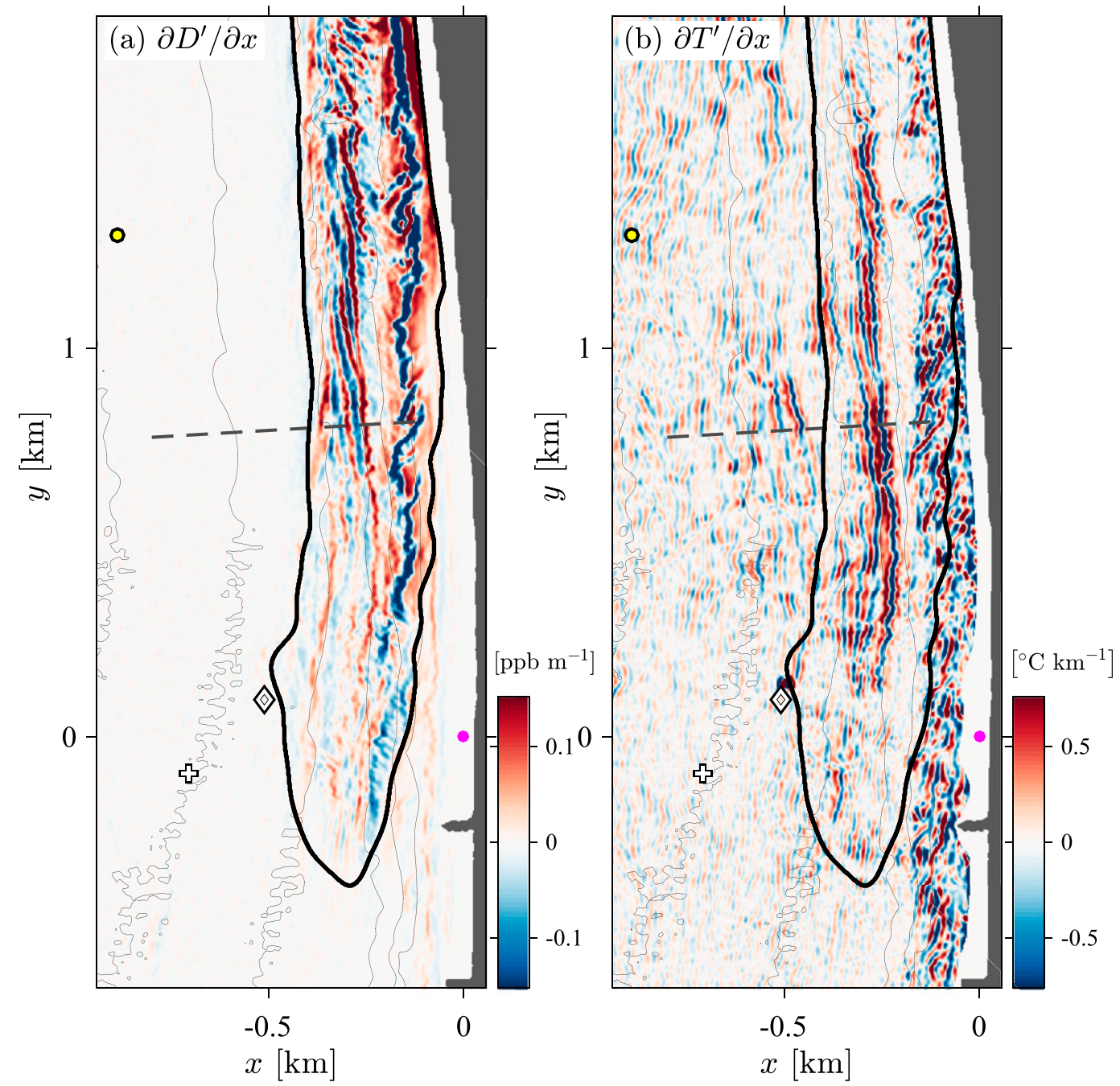

FIG. 13. Snapshot of (a) small-scale dye gradient $\partial D^{\prime} / \partial x$ and (b) small-scale temperature gradient $\partial T^{\prime} / \partial x$ vs $x$ and $y$ at $t=1155 \mathrm{~h}\left(t_{r}=6.60 \mathrm{~h}\right)$. The cross-shore MASS transect is indicated with a gray dashed line and $\bar{D}=1 \mathrm{ppb}$ contour shown in black (e.g., see Fig. 6). Location of moorings $\operatorname{Tr}$ (white cross) and W1 (yellow circle) and dye release (magenta dot) are also indicated.

During the deformation period, HF IWs with a crossshore length scale $\lambda_{\mathrm{iw}} \approx 60 \mathrm{~m}$ propagated shoreward through the IS plume, as evidenced in the small-scale $\partial D^{\prime} / \partial \tilde{x}$ and $\partial T^{\prime} / \partial \tilde{x}$ Hovmöller plots (Fig. 14). The HF IW packet at $\tilde{x} \approx-200 \mathrm{~m}$ in Fig. 13 entered the IS plume along the MASS transect at $t \approx 1040 \mathrm{~h}$ and $\tilde{x} \approx-400 \mathrm{~m}$ (start of dashed line in Fig. 14a). The packet propagated shoreward at roughly $9 \mathrm{~cm} \mathrm{~s}^{-1}$ to $\tilde{x} \approx-400 \mathrm{~m}$ where a steeper trailing front developed (red and blue banding in Fig. 14b), consistent with wave steepening, and it rapidly decelerated onshore of $\tilde{x} \approx-300 \mathrm{~m}$. Several similar features intersected the MASS transect (onshore of TA and AUV) during the deformation period, each separated by approximately $30-45 \mathrm{~min}$ (e.g., the front that passed $\tilde{x}=-500 \mathrm{~m}$ at $t=1030 \mathrm{~h}$ in Fig. 14).
The steepening and deceleration of the surface features is qualitatively consistent with weakly nonlinear extended Korteweg-de Vries (eKdV) solutions on a slope (e.g., Holloway et al. 1999). IW transformation (i.e., steepening, and breaking) primarily results from changes in depth (e.g., Sutherland et al. 2013) or stratification (e.g., Grimshaw et al. 2004). Both mechanisms are possible as HF IW approach the SZ, where $h \rightarrow h_{\mathrm{sz}}\left(h_{\mathrm{sz}}\right.$ is the depth of the outer SZ) and $N \rightarrow 0$.

Onshore of $\tilde{x}=-300 \mathrm{~m}$, the coherence between the HF IW $D^{\prime}$ and $T^{\prime}$ signals decreases. The fade in $D^{\prime} \mathrm{HF}$ IW signal is partially due to aliasing near $\bar{D}_{\text {max }}$ between $\tilde{x}=-300 \mathrm{~m}$ and $\tilde{x}=-200 \mathrm{~m}$. Based on movies of smallscale dye and temperature fields, SZ generated TRCs were also active close to shore $\left(\tilde{x} \geq-250 \mathrm{~m} \approx-2.5 L_{\mathrm{sz}}\right.$, 
(a) $\partial D^{\prime} / \partial \tilde{x}$

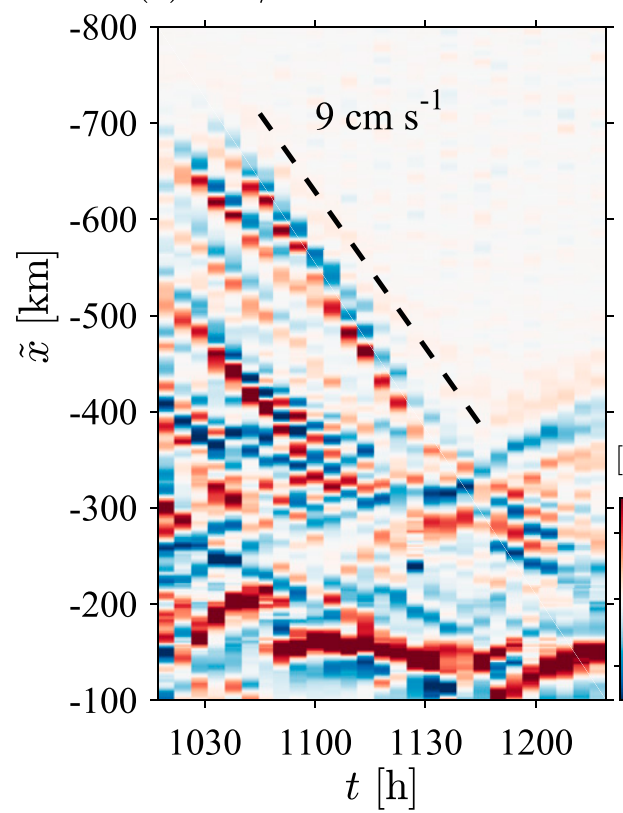

(b) $\partial T^{\prime} / \partial \tilde{x}$

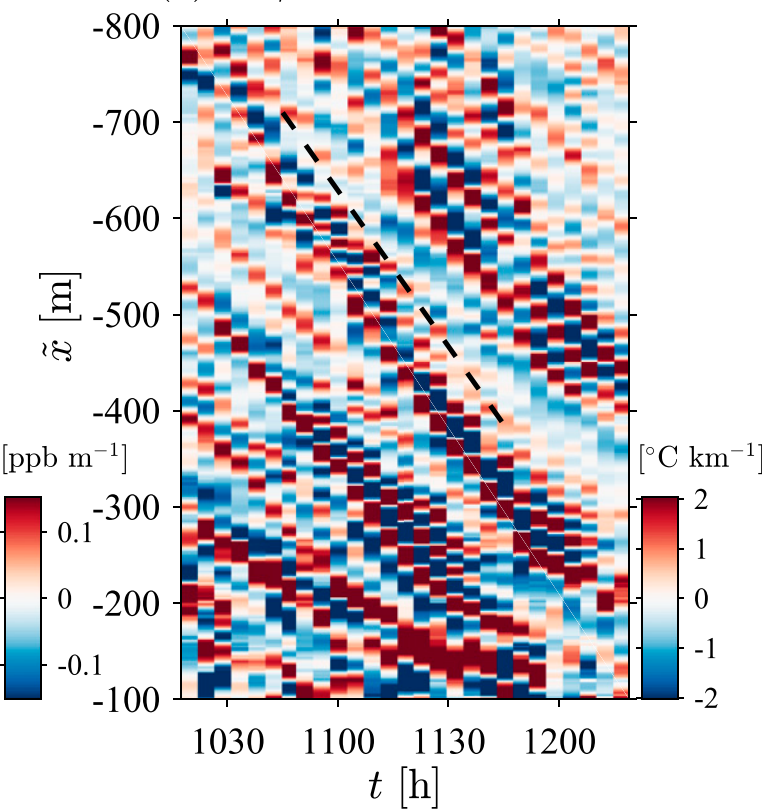

FIG. 14. Small-scale (a) dye $\partial D^{\prime} / \partial \tilde{x}$ and (b) temperature $\partial T^{\prime} / \partial \tilde{x}$ on cross-shore MASS transect (dashed line in Fig. 13) vs local, shoreline referenced cross-shore coordinate $\tilde{x}$ and time $t$ during deformation period. The dashed black line indicates an onshore progression of $9 \mathrm{~cm} \mathrm{~s}^{-1}$.

not shown). The TRC variability may be partially responsible for the decoherence of the propagating $D^{\prime}$ and $T^{\prime}$ fronts onshore of $\tilde{x}=-250 \mathrm{~m}$ in Fig. 14. The eventual disintegration of the HF IW $T^{\prime}$ signals before reaching the SZ-IS boundary $\left(\tilde{x}=-L_{\mathrm{sz}} \approx-100 \mathrm{~m}\right)$ suggests there is IW dissipation in the region $-400 \leq \tilde{x} \leq-100 \mathrm{~m}$. HF IW dissipation has been linked to vertical mixing on the shelf (e.g., Walter et al. 2012), thus mixing may be enhanced in the region onshore of AUV and TA transects where IS plume $(D, T)$ statistics were stable. However, in the near-SZ region where surface HF IW signatures disappear, NLIW can still propagate to SZ as near bed cold bores (Sinnett et al. 2018).

The LWIR-observed HF IW activity was not alongshore uniform over the study region. The temporal $\operatorname{rms}\left(\partial T^{\prime} / \partial x\right)$ between 1020 and $1230 \mathrm{~h}$ was elevated on the IS in the region offshore of $0.5 \leq y \leq 2.5 \mathrm{~km}$, with magnitudes $\geq 1^{\circ} \mathrm{C} \mathrm{km}^{-1}$ or $\approx 2-3$ times greater than to north and south (Fig. 15). The persistent small-scale gradients in this region are attributed to the HF IWs shown in Figs. 13 and 14, whereas the elevated signal onshore of roughly $2.5 L_{\mathrm{sz}}$ was due to TRC activity. The alongshore extent of the enhanced IS $\operatorname{rms}\left(\partial T^{\prime} / \partial x\right)$ bounds the region of IS plume elongation (Fig. 11), suggesting that either incident HF IWs were intensified in this region or this was where the DIT shoaled the high $N^{2}$ region (e.g., Fig. 12). The former implies HF IW mass-transport or momentum-flux-driven plume elongation, whereas the latter implicates the DIT, these mechanisms are discussed in section $4 c$.

\section{Discussion}

\section{a. Summary of results}

The 3.84-h early morning dye release evolved for $\approx 5 \mathrm{~h}$ before intensive IS in situ and aerial remote observations began. Prior to deformation, the IS plume was advected up to $8 L_{\mathrm{sz}}(800 \mathrm{~m})$ offshore and was confined to the surface, with tracer above $\tilde{z}=-3 \mathrm{~m}$ for $\tilde{x} \leq-400 \mathrm{~m}$ (Fig. 7a). As aerial observations began, the IS tracer plume was observed deforming shoreward, elongating in the alongshore and being transported south, while SZ tracer was continuously transported northward (Figs. 5ad). Large-scale $\operatorname{Tr}$ temperature and ADCP cross-shore velocity (Figs. 4a,b) indicate that the early morning offshore dye transport and mid-to-late morning deformation occurred during two phases of the DIT.

Over the deformation period, the offshore IS plume $\bar{D}=1 \mathrm{ppb}$ front propagated onshore at roughly $5 \mathrm{~cm} \mathrm{~s}^{-1}$ as the IS plume and its associated isotherms deepened at $\tilde{x} \approx-4 L_{\mathrm{sz}}$ along AUV (Figs. 4 and 7). The steepening offshore dye gradient indicates that onshore progression of the IS plume was due to advection. Similarly, the IS plume joint dye and temperature distribution was relatively stable offshore of $\tilde{x}=-4 L_{\mathrm{sz}}$, indicating that the IS plume deepening was not predominantly due to vertical mixing. 


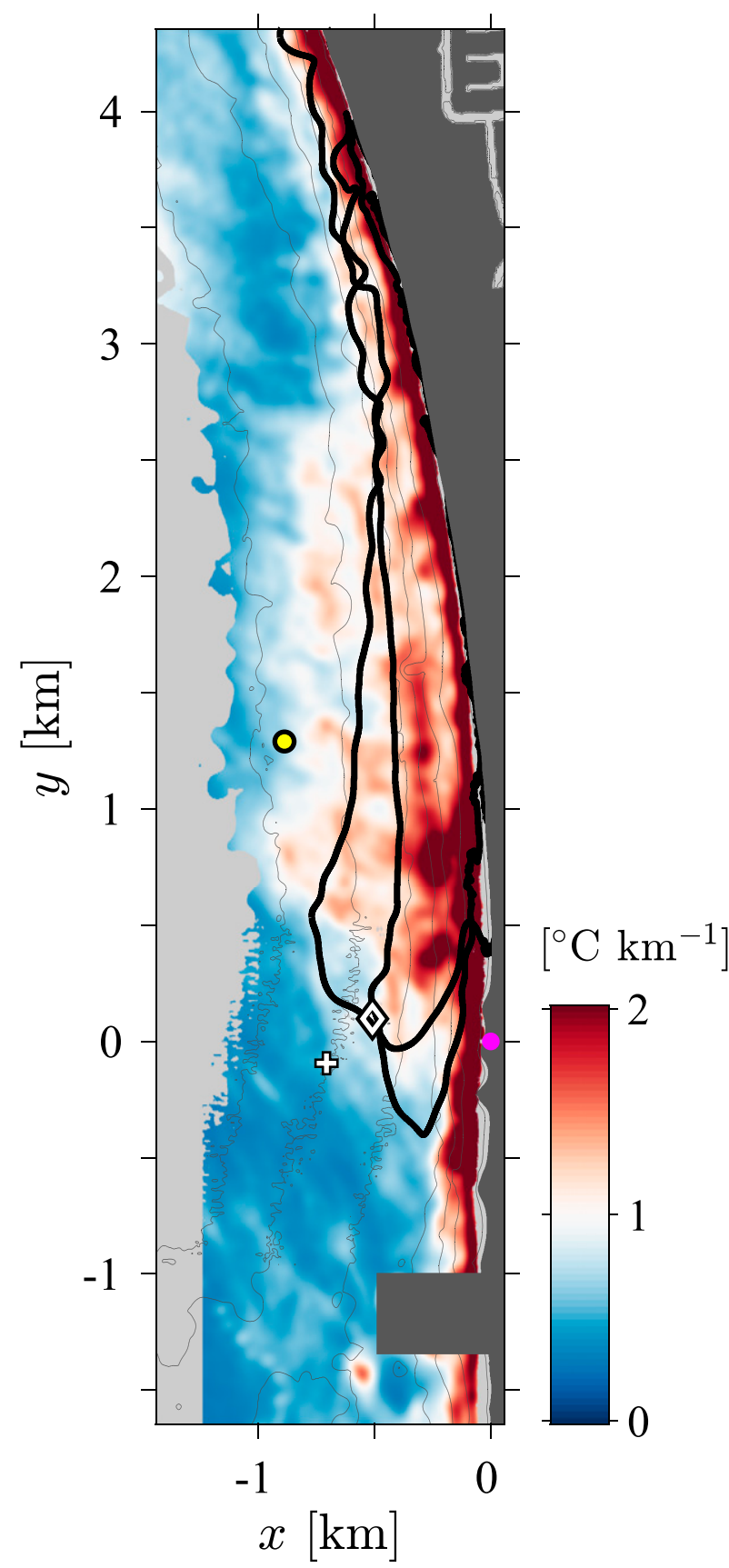

FIG. 15. Time root-mean-square of the cross-shore, small-scale temperature gradient $\operatorname{rms}\left(\partial T^{\prime} / \partial x\right)$ during the deformation period $1020 \leq t \leq 1217 \mathrm{~h}$. The rms estimate was derived from 27 MASS passes of surface $\partial T^{\prime} / \partial x$, and regions with fewer than 25 samples were removed prior to applying the large-scale spatial filter described in section 2d. Light gray are regions without data, and the wake of the Imperial Beach pier at $y \approx-1 \mathrm{~km}$ and land has been masked in dark gray.

During the deformation period, surface intensified $\mathrm{HF}$ IWs $(\approx 10$-min period) were observed at mooring $\operatorname{Tr}$ (Fig. 12). These HF IWs propagated onshore and through the IS plume at roughly $9 \mathrm{~cm} \mathrm{~s}^{-1}$ for $\tilde{x} \leq-3 L_{\mathrm{sz}}$, then decelerated in shallower water, breaking up into multiple IWs and presumably steepening (Figs. 13 and 14). The HF IW variance was enhanced in the $2-\mathrm{km}$ alongshore region of the IS plume deformation and elongation, and was much weaker just to the north and south (Fig. 15).

\section{b. Mechanism of IS plume deepening}

The IS isotherm and plume deepening observed by AUV, TA, and Tr during the deformation period could result from cross-shelf exchange flow or alongshore advection of an alongshore temperature and plume gradient, or a combination of the two. The DIT had both a cross-shore exchange structure (Figs. 4a,b) and (north-tosouth) alongshore phase propagation (Fig. 3d), indicating the presence of an IS alongshore temperature gradient during the release and deformation periods. Here, an idealized two layer cross-shelf exchange model is used to examine whether the observed plume deepening can be due to surface onshore flow associated with the DIT relaxation.

By continuity and assuming alongshore uniformity, a two layer cross-shore exchange flow, with onshore flow at the surface and compensating offshore flow at depth, drives interface deepening. At a given cross-shore location $x_{0}$, onshore transport within the surface layer is balanced by an increase in $(x, z)$ cross-sectional area $A$ of the surface layer onshore of $x_{0}$, that is,

$$
u_{\mathrm{s}} H=\partial A / \partial t
$$

where $u_{s}$ is the average surface velocity and $H(t)$ is the cross-shore uniform surface layer depth. As the IS plume remained offshore of the SZ during the deformation (Fig. 6), the approximate area onshore of AUV (i.e., with $\left.x_{0}=-400 \mathrm{~m}\right)$ is

$$
A=H L_{x}-\left(H-h_{\mathrm{sz}}\right)^{2}(2 \beta)^{-1},
$$

where $L_{x}=-\left(x_{0}+L_{\mathrm{sz}}\right), L_{\mathrm{sz}} \approx 100 \mathrm{~m}$ is the $\mathrm{SZ}$ width, and $h_{\mathrm{sz}} \approx 2 \mathrm{~m}$ is the depth at $\tilde{x}=-L_{\mathrm{sz}}$, and $\beta=0.017$ is the constant bathymetric slope. Substituting (3) into (2) and integrating (assuming constant $u_{s}$ ) gives, $u_{s} \approx$ $\Delta t^{-1}\left[\left(L_{x}+h_{\mathrm{sz}} \beta^{-1}\right) \ln \left(H_{f} / H_{i}\right)-\beta^{-1} \Delta H\right.$, relating the surface layer deepening $\Delta H=H_{f}-H_{i}$ to the exchange velocity $u_{s}$. Based on the observed plume deepening at AUV (initial $H_{i}=3 \mathrm{~m}$ and final $H_{f}=6 \mathrm{~m}$ at $\tilde{x}=-400 \mathrm{~m}$ over $\Delta t \approx 3720 \mathrm{~s}$, Figs. 7a,b), the two layer exchange model implies a $u_{s}$ of $\approx 3 \mathrm{~cm} \mathrm{~s}^{-1}$. This velocity estimate is consistent with both the $5 \mathrm{~cm} \mathrm{~s}^{-1}$ onshore progression of the $\bar{D}=1 \mathrm{ppb}$ front observed along MASS (Fig. 10a) and is of similar magnitude to the observed large-scale DIT cross-shore velocities below $z=-5 \mathrm{~m}$ at ADCP (Fig. $4 \mathrm{~b}$ ). 
Alternatively, southward advection of an alongshore gradient can appear as local temporal evolution (i.e., $\partial H / \partial t \sim-\bar{v} \partial H / \partial y$, where $\bar{v}$ is the depth averaged alongshore current). Taking the observed deepening along TA, $\partial H / \partial y \approx 1.2 \mathrm{~m} \mathrm{~km}^{-1}$, and using the southward plume front velocity $\left(|\bar{v}|<10 \mathrm{~cm} \mathrm{~s}^{-1}\right)$, gives a maximum of $\partial H / \partial t \approx 0.43 \mathrm{~m} \mathrm{~h}^{-1}$ or roughly $25 \%$ of the observed deepening at AUV. Additionally, the phase propagation of the DIT from the mooring array was much greater than the observed alongshore currents. Thus, the observed plume deepening and deformation was likely due to a cross-shore exchange flow associated with the DIT.

\section{c. Mechanisms for IS plume elongation}

The IS plume elongation (Fig. 11) suggests a near-surface alongshore straining $\partial v_{s} / \partial y$ of roughly $4.5 \mathrm{~cm} \mathrm{~s}^{-1} \mathrm{~km}^{-1}$. The presence of both northward and southward propagating features in Fig. 11 indicates that the straining may be localized to the $\approx 2 \mathrm{~km}$ IS plume elongation region $(0 \leq y \leq$ $2 \mathrm{~km}$ ), which overlaps the region of elevated HF IW surface rms $\left(\partial T^{\prime} / \partial x\right)(0.5 \leq y \leq 2.5 \mathrm{~km})$, suggesting there may be a relationship between the large-scale alongshore strain (elongation) and the IS HF IW alongshore inhomogeneity (Fig. 15).

An imbalance in the large-scale cross-shore two-layer DIT exchange flow due to excess onshore surface flow in the elongation region, that is, $u_{s}(y)$, can support an alongshore strain. Assuming the cross-shore convergence occurs over $L_{x} \approx 500 \mathrm{~m}$ (the approximate cross-shore width of the IS plume), an excess onshore $u_{s} \approx$ $2.25 \mathrm{~cm} \mathrm{~s}^{-1}$ is sufficient to support the observed straining. This implies a DIT $u_{s} \approx 5.25 \mathrm{~cm} \mathrm{~s}^{-1}$ in the elongation region, slightly larger than the onshore progression of the $\bar{D}=1 \mathrm{ppb}$ front. This would also require the DIT to have a relatively short $\approx 4 \mathrm{~km}$ alongshore length scale, either due to direction of propagation or alongshore gradients induced by the geometry of the San Diego Bight.

HF IWs can drive cross-shore mass transport. A single nondissipative internal solitary wave induces horizontal mass displacement that increases with nonlinearity, represented by the ratio of IW fluid velocity $u_{\text {iw }}$ to wave celerity $c$, and with wavelength (i.e., $u_{\mathrm{iw}} / c$ and $\lambda_{\text {iw }}$; e.g., Lamb 1997). Based on observed IW characteristics $\left(u_{\mathrm{iw}} / c \approx 0.11\right.$ and $\left.\lambda_{\mathrm{iw}} \approx 60 \mathrm{~m}\right)$, the individual solitary IW surface displacement was potentially $\mathcal{O}(1.5) \mathrm{m}$ [Lamb 1997, (A8)]. In a wave averaged sense, incremental solitary wave displacements lead to mass transport (e.g., Shroyer et al. 2010; Zhang et al. 2015), analogous to surface gravity wave Stokes drift (Henderson 2016). Over the deformation period the HF IWs potentially account for a net onshore displacement of roughly $15 \mathrm{~m}$ (i.e., passage of 10 waves), or an IW induced $u_{s} \approx 0.2 \mathrm{~cm} \mathrm{~s}^{-1}$.
Thus, internal solitary wave Stokes drift was insufficient to support the observed elongation.

In addition to IW Stokes drift, IWs also have a momentum flux, akin to a radiation stress. Wavedissipation-induced divergence of IW momentum flux generates cross-shore pressure gradients (e.g., Wunsch 1971; Suanda et al. 2017) and, for obliquely incident IWs, alongshore currents (e.g., Thorpe 1999; Zikanov and Slinn 2001). In the region $-4 L_{\mathrm{sz}} \leq \tilde{x} \leq-2.5 L_{\mathrm{sz}}$, observed HF IWs appear to steepen and dissipate (Fig. 14) and HF IW activity was concentrated in the elongation region (Fig. 15). In analogy to alongshore gradients in surface gravity wave height (and radiation stress) generating alongshore SZ pressure gradients and circulation cells (Bowen 1969), an elevated IW energy flux and dissipation in the region of the IS plume might create a baroclinic pressure driven alongshore elongation. In the context of IWs incident on nearcritical slopes, breaking and along-slope flow is generated near the bottom or within a critical layer (e.g., Zikanov and Slinn 2001), and thus are not likely to cause nearsurface currents. However, in the present case of HF lowmode or solitary-like waves dissipating near shore, the vertical structure or velocity scale is unclear.

As the DIT was responsible for the observed largescale cross-shore exchange flow, and the magnitude of the exchange velocity (inferred from velocities below $z<-5 \mathrm{~m}$ ) were of similar magnitude as needed to support both deepening and straining, the DIT was therefore also likely responsible for the IS plume alongshore elongation. While other possible mechanisms can induce strain, they were not consistent with observations. Although, a contribution from HF IW momentum flux cannot, at present, be discounted. In either case (DIT or HF IW momentum flux), this implies an inhomogeneity of the DIT over the fairly narrow alongshore elongation region. If the HF IWs were generated through an instability of the DIT, then spatial patterns of the DIT would subsequently be reflected in the HF IW field, hence the patterns in Fig. 15.

\section{d. Influence of tracer release timing}

Previous SZ dye release experiments released from mid to late morning and observed alongshore SZ transport over several kilometers and dye confined to within $2 L_{\mathrm{sz}}-3 L_{\mathrm{sz}}$ (e.g., Grant et al. 2005; Clark et al. 2010; HallyRosendahl et al. 2015). These three dye releases took place in Southern California in May, September, or October when solar forcing was strong. A midday tidal inlet dye release during strong obliquely incident waves and alongshore wind, had dye transported alongshore in the SZ for about $9 \mathrm{~km}$ and also largely confined to $2 L_{\mathrm{sz}}-3 L_{\mathrm{sz}}$ (Feddersen et al. 2016). The observed SZ-IS temperature difference was $\approx 1^{\circ} \mathrm{C}$, due to warm dye-laden 
ebb tidal-inlet water in the SZ. In contrast, following R2, dye was observed out to $\tilde{x}=-8 L_{\mathrm{sz}}$, and the subsequent IS plume shoreward deformation and late morning to afternoon southward transport (Fig. 5), is in stark contrast to the more canonical SZ plume toward the north $(y \geq 3 \mathrm{~km}$, Fig. 5). Here, the influence of the early morning release timing (0518-0908 $\mathrm{h}$ ) relative to the DIT and solar cycle is examined.

Tracer release began when the SZ was colder than the surface IS (i.e., $t<0800 \mathrm{~h}$, Fig. 4c). As such, tracer exchanged onto the IS prior to $0800 \mathrm{~h}$ would have been expected to preferentially spread offshore at depth, largely following the tracer release isotherm (i.e., weak mixing). In a modeling study of TRC SZ-IS exchange without solar forcing, SZ released tracer was transported offshore in an IS subsurface layer due to the interaction of TRCs and IS stratification (Kumar and Feddersen 2017b). However, despite the SZ being colder than the near-surface IS during much of the release, the IS plume was surface intensified because the DIT drew even colder water onshore at depth preventing IS plume subduction. If the DIT had not occurred, the IS plume may have remained closer to shore with subduction of the dye maximum, as observed farther north at $y=2.5 \mathrm{~km}$ near the boundary between SZ and IS plumes (Fig. 8).

In addition to influencing the vertical structure and cross-shore extent of the IS plume during the release period, the DIT also modulated the IS plume thermal evolution. Hally-Rosendahl et al. (2014) observed a SZ and IS $(D, T)$ distribution, with higher average SZ dye and temperature and stronger IS stratification. Here, a similar $(D, T)$ relationship was observed prior to the deformation period (circles, Fig. 9), although with some differences. The Hally-Rosendahl et al. (2014) dye was released in $T>19^{\circ} \mathrm{C}$ and was diapycnally mixed to $T=$ $18^{\circ} \mathrm{C}$ on the IS within $2 L_{\mathrm{sz}}$. Here, the IS plume tracer was quasi-adiabatically advected to a depth of $6 \mathrm{~m}$ at $4 L_{\mathrm{sz}}-$ $6 L_{\mathrm{sz}}$ with cross-isotherm dye mixing limited to $\leq 0.5^{\circ} \mathrm{C}$.

Additionally, the mid-to-late morning increase in SZ-IS plume temperature separation (Fig. 9) resulted from the early morning cross-shore plume advection (i.e., the $8 L_{\mathrm{sz}}$ cross-shore extent), and a reduced solar heating in deeper water. As such, by the end of the deformation period, the $\mathrm{SZ}$ and IS plumes had $\mathrm{a} \approx 1^{\circ} \mathrm{C}$ mean temperature difference even though they had similar mean dye concentration (Fig. 9). Subsequently, during and after deformation, the warmer SZ may have been a thermal barrier for the IS plume. Omand et al. (2011) argued a similar mechanism prevented an IS phytoplankton bloom from reaching the warm SZ following a large IW upwelling event.

Shoreline-released tracer released at alternate phases of either the internal tide or the solar cycle would be expected to evolve differently. In particular, tracer released during the deformation period (warm surfzone) would likely not have formed the IS plume and the overall alongshore plume extent would have largely followed the northward SZ currents. Alternatively, if tracer had been released even earlier in the DIT cooling phase (i.e., around midnight) with SZ colder than nearsurface IS, even more tracer may have been advected onto the IS with subsequent southward advection over the deformation and elongation period. Thus, release timing relative to the solar cycle and any internal tide events is relevant to the transport and dispersion of shoreline-released tracers (e.g., human pathogens, or larvae) to the IS and also likely for the IS to the SZ.

\section{Summary and conclusions}

An early-morning SZ tracer release coinciding with the cooling phase of the DIT resulted in, an anomalously large (relative to previously observed SZ dye release experiments) $8 L_{\mathrm{sz}}$ cross-shore plume width after $3-5 \mathrm{~h}$, extending well onto the IS. During the subsequent DIT warming phase (next $\approx 2 \mathrm{~h}$ ), this IS plume deformed (narrowed) cross-shore to $5 L_{\mathrm{sz}}$, vertically thickened by up to $3 \mathrm{~m}$, and strained (elongated) alongshore, yet remained offshore of the SZ. This large-scale IS plume evolution is consistent with a simple two-layer crossshore exchange model.

The DIT-augmented cross-shore tracer transport also coincided with the transition from nighttime cooling to solar heating. The shallow SZ warmed more rapidly than the near-surface IS, inducing separate SZ and IS plume $T$ evolution. The development of a positive crossshore temperature gradient may have blocked the IS plume from entering the SZ. Additionally, a DIT alongshore gradient (over $\approx 2 \mathrm{~km}$ ) could support the observed IS plume elongation. Small-scale processes, for example, TRC and HF IW, interacted with the IS plume, likely contributing to vertical mixing onshore of $4 L_{\mathrm{sz}}$ and SZ-IS exchange. Coupled with opposing SZ-IS alongshore currents, the release timing relative to both the DIT and solar cycle resulted in the $\approx 9 \mathrm{~km}$ alongshore plume extent in roughly $12 \mathrm{~h}$ (i.e., $\mathrm{SZ}$ plume $\approx 7 \mathrm{~km}$ north of release and IS plume $\approx 2 \mathrm{~km}$ south of the release).

These observations demonstrate that nearshore tracer exchange is influenced by both SZ and IS processes spanning a broad range of scales. Here, we have shown that the interaction and relative phasing of the DIT with solar warming can have a significant effect on the evolution of shoreline released tracer over $\approx 5-12 \mathrm{~h}$.

Acknowledgments. Thanks to two anonymous reviewers who greatly helped improve this manuscript. 
This work was funded under the CSIDE grant by the National Science Foundation (NSF OCE-1459389), and through the NSF Graduate Research Fellowship Program. Data were made available in part by SIO CDIP and the Tijuana River National Estuary Research Reserve and are available through the CSIDE web page (https://scripps.ucsd.edu/projects/cside/) or by contacting the corresponding author. The U.S. Navy provided access to Navy property for data collection. We thank Ken Melville, Luc Lenain, Nick Statom, and Stephen Holleman for acquisition and preliminary processing of MASS data. We thank YMCA: Camp Surf for providing a base of operations; the cities of Imperial Beach and Coronado, the U.S. Navy and CA State Parks for accommodating our research activities; and the numerous Imperial Beach lifeguards, UCSD/SIO students, and volunteers for efforts to keep beachgoers safe and monitor surfzone instrumentation.

\section{REFERENCES}

Austin, J. A., and S. J. Lentz, 2002: The inner shelf response to wind-driven upwelling and downwelling. J. Phys. Oceanogr., 32, 2171-2193, https://doi.org/10.1175/1520-0485(2002)032<2171: TISRTW $>2.0 . C O ; 2$.

Barbier, E. B., S. D. Hacker, C. Kennedy, E. W. Koch, A. C. Stier, and B. R. Silliman, 2011: The value of estuarine and coastal ecosystem services. Ecol. Monogr., 81, 169-193, https://doi.org/ 10.1890/10-1510.1.

Bowen, A. J., 1969: Rip currents: 1. Theoretical investigations. J. Geophys. Res., 74, 5467-5478, https://doi.org/10.1029/ JC074i023p05467.

Brown, J. A., J. H. MacMahan, A. J. H. M. Reniers, and E. B. Thornton, 2009: Surf zone diffusivity on a rip-channeled beach. J. Geophys. Res., 114, C11015, https://doi.org/10.1029/ 2008JC005158.

,,$---\ldots$, and ——, 2015: Field observations of surf zoneinner shelf exchange on a rip-channeled beach. J. Phys. Oceanogr., 45, 2339-2355, https://doi.org/10.1175/JPO-D14-0118.1.

Clark, D. B., F. Feddersen, and R. T. Guza, 2010: Cross-shore surfzone tracer dispersion in an alongshore current. J. Geophys. Res., 115, C10035, https://doi.org/10.1029/2009JC005683.

_ S. Elgar, and B. Raubenheimer, 2012: Vorticity generation by short-crested wave breaking. Geophys. Res. Lett., 39, L24604, https://doi.org/10.1029/2012GL054034.

— L. Lenain, F. Feddersen, E. Boss, and R. T. Guza, 2014: Aerial imaging of fluorescent dye in the near shore. J. Atmos. Oceanic Technol., 31, 1410-1421, https://doi.org/10.1175/ JTECH-D-13-00230.1.

Farrar, J. T., C. J. Zappa, R. A. Weller, and A. T. Jessup, 2007: Sea surface temperature signatures of oceanic internal waves in low winds. J. Geophys. Res., 112, C06014, https://doi.org/ 10.1029/2006JC003947.

Farrow, D. E., and J. C. Patterson, 1993: On the response of a reservior sidearm to diurnal heating and cooling. J. Fluid Mech., 246, 143-161, https://doi.org/10.1017/S0022112093000072.

Feddersen, F., 2012: Scaling surf zone turbulence. Geophys. Res. Lett., 39, L18613, https://doi.org/10.1029/2012GL052970.
- and R. T. Guza, 2003: Observations of nearshore circulation: Alongshore uniformity. J. Geophys. Res., 108, 3006, https:// doi.org/10.1029/2001JC001293.

—, M. Olabarrieta, R. T. Guza, D. Winters, B. Raubenheimer, and S. Elgar, 2016: Observations and modeling of a tidal inlet dye tracer plume. J. Geophys. Res. Oceans, 121, 7819-7844, https://doi.org/10.1002/2016JC011922.

Fong, D. A., and M. T. Stacey, 2003: Horizontal dispersion of a near-bed coastal plume. J. Fluid Mech., 489, 239-267, https:// doi.org/10.1017/S002211200300510X.

Grant, S. B., J. H. Kim, B. H. Jones, S. A. Jenkins, J. Wasyl, and C. Cudaback, 2005: Surf zone entrainment, along-shore transport, and human health implications of pollution from tidal outlets. J. Geophys. Res., 110, C10025, https://doi.org/ 10.1029/2004JC002401.

Grimshaw, R., E. Pelinovsky, T. Talipova, and A. Kurkin, 2004: Simulation of the transformation of internal solitary waves on oceanic shelves. J. Phys. Oceanogr., 34, 2774-2791, https:// doi.org/10.1175/JPO2652.1.

Hally-Rosendahl, K., F. Feddersen, and R. T. Guza, 2014: Crossshore tracer exchange between the surfzone and inner-shelf. J. Geophys. Res. Oceans, 119, 4367-4388, https://doi.org/10.1002/ 2013JC009722.

,,-- D. B. Clark, and R. T. Guza, 2015: Surfzone to inner-shelf exchange estimated from dye tracer balances. J. Geophys. Res. Oceans, 120, 6289-6308, https://doi.org/10.1002/2015JC010844.

Hendershott, M., 1981: Long waves and ocean tides. Evolution of Physical Oceanography, B. A. Warren and C. Wunsch, Eds., MIT Press, 292-341.

Henderson, S. M., 2016: Upslope internal-wave Stokes drift, and compensating downslope eulerian mean currents, observed above a lakebed. J. Phys. Oceanogr., 46, 1947-1961, https:// doi.org/10.1175/JPO-D-15-0114.1.

Holloway, P. E., E. Pelinovsky, and T. Talipova, 1999: A generalized Korteweg-de Vries model of internal tide transformation in the coastal zone. J. Geophys. Res., 104, 18333-18350, https://doi.org/10.1029/1999JC900144.

Horwitz, R., and S. J. Lentz, 2014: Inner-shelf response to crossshelf wind stress: The importance of the cross-shelf density gradient in an idealized numerical model and field observations. J. Phys. Oceanogr., 44, 86-103, https://doi.org/10.1175/ JPO-D-13-075.1.

Johnson, D., and C. Pattiaratchi, 2004: Transient rip currents and nearshore circulation on a swell-dominated beach. J. Geophys. Res., 109, C02026, https://doi.org/10.1029/2003JC001798.

Jones, N. L., R. J. Lowe, G. Pawlak, D. A. Fong, and S. G. Monismith, 2008: Plume dispersion on a fringing coral reef system. Limnol. Oceanogr., 53, 2273-2286, https://doi.org/ 10.4319/lo.2008.53.5_part_2.2273.

Klymak, J. M., and J. N. Moum, 2003: Internal solitary waves of elevation advancing on a shoaling shelf. Geophys. Res. Lett., 30, 2045, https://doi.org/10.1029/2003GL017706.

Kumar, N., and F. Feddersen, 2017a: The effect of Stokes drift and transient rip currents on the inner shelf. Part II: With stratification. J. Phys. Oceanogr., 47, 243-260, https://doi.org/ 10.1175/JPO-D-16-0077.1.

— , and — 2017b: A new offshore transport mechanism for shoreline-released tracer induced by transient rip currents and stratification. Geophys. Res. Lett., 44, 2843-2851, https:// doi.org/10.1002/2017GL072611.

__ _ _ - S. Suanda, Y. Uchiyama, and J. McWilliams, 2016: Mid- to inner-shelf coupled ROMS-SWAN model-data comparison of currents and temperature: Diurnal and semi-diurnal 
variability. J. Phys. Oceanogr., 46, 841-862, https://doi.org/ 10.1175/JPO-D-15-0103.1.

Lamb, K. G., 1997: Particle transport by nonbreaking, solitary internal waves. J. Geophys. Res. Oceans, 102, 18641-18660, https://doi.org/10.1029/97JC00441.

Lentz, S. J., 2001: The influence of stratification on the winddriven cross-shelf circulation over the North Carolina shelf. J. Phys. Oceanogr., 31, 2749-2760., https://doi.org/10.1175/ 1520-0485(2001)031<2749:TIOSOT>2.0.CO;2.

— and M. R. Fewings, 2012: The wind- and wave-driven innershelf circulation. Ann. Rev. Mar. Sci., 4, 317-343, https:// doi.org/10.1146/annurev-marine-120709-142745.

Lerczak, J. A., M. C. Hendershott, and C. D. Winant, 2001: Observations and modeling of coastal internal waves driven by a diurnal sea breeze. J. Geophys. Res., 106, 19715-19729, https://doi.org/10.1029/2001JC000811.

Longuet-Higgins, M. S., 1970a: Longshore currents generated by obliquely incident sea waves: 1. J. Geophys. Res., 75, 67786789, https://doi.org/10.1029/JC075i033p06778.

_ 1970b: Longshore currents generated by obliquely incident sea waves: 2. J. Geophys. Res., 75, 6790-6801, https://doi.org/ 10.1029/JC075i033p06790.

Lucas, A. J., P. J. S. Franks, and C. L. Dupont, 2011: Horizontal internal-tide fluxes support elevated phytoplankton productivity over the inner continental shelf. Limnol. Oceanogr. Fluids Environ., 1, 56-74, https://doi.org/10.1215/215736981258185.

Marmorino, G. O., G. B. Smith, and G. J. Lindemann, 2004: Infrared imagery of ocean internal waves. Geophys. Res. Lett., 31, L11309, https://doi.org/10.1029/2004GL020152.

Melville, W. K., L. Lenain, D. R. Cayan, M. Kahru, J. P. Kleissl, P. F. Linden, and N. M. Statom, 2016: The modular aerial sensing system. J. Atmos. Oceanic Technol., 33, 1169-1184, https://doi.org/10.1175/JTECH-D-15-0067.1.

Molina, L., G. Pawlak, J. R. Wells, S. G. Monismith, and M. A. Merrifield, 2014: Diurnal cross-shore thermal exchange on a tropical forereef. J. Geophys. Res. Oceans, 119, 6101-6120, https://doi.org/10.1002/2013JC009621.

Monismith, S. G., J. Imberger, and M. L. Morison, 1990: Convective motions in the sidearm of a small reservior. Limnol. Oceanogr., 35, 1676-1702, https://doi.org/10.4319/lo.1990. 35.8.1676.

Moniz, R. J., D. A. Fong, C. B. Woodson, S. K. Willis, M. T. Stacey, and S. G. Monismith, 2014: Scale-dependent dispersion within the stratified interior on the shelf of northern Monterey Bay. J. Phys. Oceanogr., 44, 1049-1064, https://doi.org/10.1175/ JPO-D-12-0229.1.

Morgan, S. G., A. L. Shanks, J. H. MacMahan, A. J. Reniers, and F. Feddersen, 2018: Planktonic subsidies to surf-zone and intertidal communities. Ann. Rev. Mar. Sci., 10, 345-369, https://doi.org/10.1146/annurev-marine-010816-060514.

Nam, S., and U. Send, 2011: Direct evidence of deep water intrusions onto the continental shelf via surging internal tides. J. Geophys. Res., 116, C05004, https://doi.org/10.1029/ 2010JC006692.

Omand, M. M., J. J. Leichter, P. J. S. Franks, R. T. Guza, A. J. Lucas, and F. Feddersen, 2011: Physical and biological processes underlying the sudden surface appearance of a red tide in the nearshore. Limnol. Oceanogr., 56, 787-801, https:// doi.org/10.4319/lo.2011.56.3.0787.

Pineda, J., 1999: Circulation and larval distribution in internal tidal bore warm fronts. Limnol. Oceanogr., 44, 1400-1414, https:// doi.org/10.4319/lo.1999.44.6.1400.
_ J. A. Hare, and S. Sponaugle, 2007: Larval transport and dispersal in the coastal ocean and consequences for population connectivity. Oceanography, 20, 22-39, https://doi.org/10.5670/ oceanog.2007.27.

Rainville, L., and R. Pinkel, 2001: Wirewalker: An autonomous wave-powered vertical profiler. J. Atmos. Oceanic Technol., 18, 1048-1051., https://doi.org/10.1175/1520-0426(2001)018<1048: WAAWPV $>2.0 . \mathrm{CO} ; 2$.

Shroyer, E. L., J. N. Moum, and J. D. Nash, 2010: Vertical heat flux and lateral mass transport in nonlinear internal waves. Geophys. Res. Lett., 37, L08601, https://doi.org/10.1029/ 2010GL042715.

Sinnett, G., F. Feddersen, A. J. Lucas, G. Pawlak, and E. Terrill, 2018: Observations of nonlinear internal wave run-up to the surfzone. J. Phys. Oceanogr., 48, 531-554, https://doi.org/ 10.1175/JPO-D-17-0210.1.

Smith, R. L., 1981: A comparison of the structure and variability of the flow field in three coastal upwelling regions: Oregon, northwest Africa, and Peru. Coastal Upwelling, F. A. Richards, Ed., Coastal and Estuarine Sciences, Vol. 1, Amer. Geophys. Union, 107-118, https://doi.org/10.1029/CO001p0107.

Stacey, M. T., E. A. Cowen, T. M. Powell, E. Dobbins, S. G. Monismith, and J. R. Koseff, 2000: Plume dispersion in a stratified, near-coastal flow: Measurements and modeling. Cont. Shelf Res., 20, 637-663, https://doi.org/10.1016/S02784343(99)00061-8.

Suanda, S. H., and F. Feddersen, 2015: A self-similar scaling for cross-shelf exchange driven by transient rip currents. Geophys. Res. Lett., 42, 5427-5434, https://doi.org/10.1002/ 2015 GL063944.

- _ - and N. Kumar, 2017: The effect of barotropic and baroclinic tides on coastal stratification and mixing. J. Geophys. Res. Oceans, 122, $10156-10173$, https://doi.org/10.1002/ 2017JC013379.

Sundermeyer, M. A., and J. R. Ledwell, 2001: Lateral dispersion over the continental shelf: Analysis of dye release experiments. J. Geophys. Res., 106, 9603-9621, https://doi.org/10.1029/ 2000JC900138.

Sutherland, B. R., K. J. Barrett, and G. N. Ivey, 2013: Shoaling internal solitary waves. J. Geophys. Res. Oceans, 118, 41114124, https://doi.org/10.1002/jgrc.20291.

Thorpe, S. A., 1999: The generation of alongslope currents by breaking internal waves. J. Phys. Oceanogr., 29, 29-38., https://doi.org/ 10.1175/1520-0485(1999)029<0029:TGOACB > 2.0.CO;2.

Ulloa, H. N., K. A. Davis, S. G. Monismith, and G. Pawlak, 2018: Temporal variability in thermally driven cross-shore exchange: The role of semidiurnal tides. J. Phys. Oceanogr., 48, 1513-1531, https://doi.org/10.1175/JPO-D-17-0257.1.

Walsh, E. J., R. Pinkel, D. E. Hagan, R. A. Weller, C. W. Fairall, D. P. Rogers, S. P. Burns, and M. Baumgartner, 1998: Coupling of internal waves on the main thermocline to the diurnal surface layer and sea surface temperature during the tropical ocean-global atmosphere coupled ocean-atmosphere response experiment. J. Geophys. Res., 103, 12 613-12 628, https://oi.org/ 10.1029/98JC00894.

Walter, R. K., C. B. Woodson, R. S. Arthur, O. B. Fringer, and S. G. Monismith, 2012: Nearshore internal bores and turbulent mixing in southern Monterey Bay. J. Geophys. Res., 117, C07017, https://doi.org/10.1029/2012JC008115. , E. C. Reid, K. A. Davis, K. J. Armenta, K. Merhoff, and N. J. Nidzieko, 2017: Local diurnal wind-driven variability and upwelling in a small coastal embayment. J. Geophys. Res. Oceans, 122, 955-972, https://doi.org/10.1002/2016JC012466. 
Washburn, L., and E. McPhee-Shaw, 2013: Coastal transport processes affecting inner-shelf ecosystems in the california current system. Oceanography, 26, 34-43, https://doi.org/10.5670/oceanog.2013.43.

Winant, C. D., 1974: Internal surges in coastal waters. J. Geophys. Res., 79, 4523-4526, https://doi.org/10.1029/JC079i030p04523.

Wunsch, C., 1971: Note on some reynolds stress effects of internal waves on slopes. Deep-Sea Res. Oceanogr. Abstr., 18, 583-591, https://doi.org/10.1016/0011-7471(71)90124-0.
Zhang, S., M. H. Alford, and J. B. Mickett, 2015: Characteristics, generation and mass transport of nonlinear internal waves on the washington continental shelf. J. Geophys. Res. Oceans, 120, 741-758, https://doi.org/ 10.1002/2014JC010393.

Zikanov, O., and D. N. Slinn, 2001: Along-slope current generation by obliquely incident internal waves. J. Fluid Mech., 445, 235261, https://doi.org/10.1017/S0022112001005560. 